\title{
CHROMOSOME PAIRING AND SYNAPTONEMAL COMPLEX FORMATION IN WHEAT-RYE HYBRIDS
}

\author{
by \\ XINGZHI WANG ${ }^{1,2)}$ and PREBEN BACH HOLM ${ }^{1)}$ \\ 1)Department of Physiology, Carlsberg Laboratory, \\ Gamle Carlsberg Vej 10, DK-2500 Copenhagen Valby \\ ${ }^{2}$ Institute of Genetics, Academia Sinica, Beijing, China
}

Keywords: Crossing over, homoeologous chromosomes

\begin{abstract}
The effect of chromosome 5B on chromosome pairing and chiasma formation in hybrids between allohexaploid wheat and diploid rye has been analyzed by ultrastructural investigations of synaptonemal complexes in spread silver stained microsporocytes of hybrids nullisomic for chromosome $5 B$, euploid hybrids and hybrids carrying an isochromosome for the long arm of chromosome 5B. At metaphase $\mathrm{I}$, there were a mean number of 6.9 chiasmata per cell in the nullisomic $5 \mathrm{~B}$ hybrids and 0.7 chiasmata per cell in the euploid hybrids, while the monoisosomic $5 \mathrm{BL}$ hybrids were virtually achiasmatic, with the exception of the isochromosomes where chiasmata formed regularly between the homologous/identical arms. Up to $40-50 \%$ of the complement paired with a synaptonemal complex in the three genotypes, giving rise to multiple associations often involving nearly all lateral components. In the nullisomic $5 \mathrm{~B}$ hybrids the number of pairing partner exchanges per lateral component engaged in synapsis at zygotene was twice that found in the two other genotypes. It is concluded that nullisomy for chromosome $5 \mathrm{~B}$ in wheat-rye hybrids results both in a lower stringency of synapsis and in permissiveness for crossing over between homoeologues.
\end{abstract}

\section{INTRODUCTION}

The present paper is addresed to a light and electron microscopic analysis of meiosis in hybrids between allohexaploid wheat, Triticum aestivum cv. Chinese Spring and diploid rye, Secale cereale. The study is a part of an investigation aiming at characterizing the effect of chromosome 5B on synapsis and chiasma formation in wheat (10). Analysis of synaptonemal complex formation in allohexaploid wheat is, however, complicated and time consuming even when using the surface spreading technique. A simpler situation is encountered in haploids (trihaploids) of wheat where the effect of chromosome $5 \mathrm{~B}$ on chromosome pairing and synaptonemal complex formation between the ho- moeologues and nonhomologues of the A, B and $D$ genomes can be analyzed in the absence of competing homologous partners. An investigation of chromosome pairing and synaptonemal complex formation in trihaploid wheat with and without chromosome $5 \mathrm{~B}$ thus revealed a nearly twofold increase in the number of pairing partner exchanges per lateral component at zygotene in the absence of chromosome $5 \mathrm{~B}$ (25) when compared to euhaploid wheat. A major drawback is, however, that nullisomic SB haploids are difficult to obtain in sufficient numbers by anther culture as they either undergo spontaneous chromosome doubling or die before the tillering stage (25).

In the cytogenetic assessment of the effect of 
various genetic loci or chromosome arms on chiasma formation between homoeologues it is common practice to use hybrids between wheat and related species such as rye. Classical light microscopic studies of wheat-rye hybrids (genomic constitution $\mathrm{A}, \mathrm{B}, \mathrm{D}$ and $\mathrm{R}$ ) have disclosed that chiasma formation in these hybrids is as regular and of nearly the same frequency in the presence/absence of chromosome $5 \mathrm{~B}$ as in trihaploid wheat. RILEY (19) reported that in five wheat haploids nullisomic for chromosome $5 \mathrm{~B}$ there were a mean number of 3.72 bivalents, 1.64 trivalents and 0.07 quadrivalents while in nullisomic 5B wheat-rye hybrids there were 3.36 bivalents, 0.88 trivalents and 0.08 quadrivalents. In the euhaploids there were a mean of 1.05 bivalents and 0.02 trivalents in the 12 plants analyzed, while 0.48 bivalents and no trivalents or associations of higher valency were found in euploid wheat-rye hybrids. Subsequent work have suggested, however, that rye chromosomes, in particular if present in extra dosage may increase the chiasma formation between the wheat homoeologues $(6,17,18,21)$. Although rye chromosomes show a great deal of homology with the chromosomes of the A, B and $D$ genomes (15), they rarely recombine with the wheat chromosomes. METTIN et al. (14) reported that in C-banded metaphase I preparations of wheat-rye hybrids only $1.3 \%$ of the chiasmata had formed between either a rye and a wheat chromosome or between two nonhomologous rye chromosomes. A similar conclusion was reached in an analysis of wheat-rye hybrids where chromosome 5B had been substituted with chromosome $5 \mathrm{D}$, showing a preferential chiasma formation between the $A$ and $D$ genomes of wheat (11). In the presence of the ph 1 b mutation on the long arm of chromosome $5 B(24)$, there was in wheat-rye hybrids a mean of 4.92 bivalents, 1.80 trivalents and 0.08 quadrivalents per cell, but on the average only 0.72 rye chromosome per cell had formed a chiasma with a wheat chromosome (2). The long arm of rye chromosome 1 appears to have the greatest affinity to wheat chromosomes (17). A recombination frequency of $1.5 \%$ has been measured between the long arm of rye chromosome 1 and wheat chromosome arms in a translocation line of hexaploid wheat (replacement of the long arm of chromosome 1D with the long arm of rye chromosome 1), homozygous for the phlb mutation (13).

The lack of crossing over in wheat-rye hybrids cannot be attributed to asynapsis. Ultrastructural investigations, using serial sectioning and three dimensional reconstruction of hybrids between rye and hexaploid wheat revealed in one serially sectioned nucleus that $35 \%$ of the complement was combined with a synaptonemal complex. Recombination nodules of normal morphology were also identified. In hybrids between rye and tetraploid wheat, $T$. turgidum $(2 \times A, 2 \times B) 25 \%$ of the complement had synapsed in one partly reconstructed nucleus and pairing partner exchanges involving four chromosomes were identified. In hybrids between diploid $T$. tauschii (D genome) and rye the synapsis appeared to be very limited (1).

It is the aim of the present study to investigate at the ultrastructural level the effect of chromosome $5 \mathrm{~B}$ on synaptonemal complex formation in wheat-rye hybrids with or without chromosome 5B. In addition a hybrid carrying an isochromosome for $5 \mathrm{BL}$ is included for study to assess whether there is a dosage effect of the long arm of 5B on synapsis and chiasma formation in these hybrids. The significance of the results in relation to other studies on the effect of chromosome $5 \mathrm{~B}$ is discussed in (10).

\section{MATERIALS AND METHODS}

Wheat-rye hybrids nullisomic for chromosome 5B, euploid hybrids and hybrids carrying an isochromosome for the long arm of chromosome $5 B$ were obtained by pollination of $T$. aestivum cv. Chinese Spring monosomic for chromosome 5B with pollen from Secale cereale, Ptili K135. The rye variety Ptili was kindly provided by Dr. Sven B. ANDERSEN, The Royal Veterinary and Agricultural University, Copenhagen. The seeds obtained from the cross were grown in a heated green house at $20^{\circ} \mathrm{C}$.

Squashing and staining/N-banding of root tip chromosome complements as well as metaphase I complements and the processing of the material for electron microscopy were performed as previously described $(9,25)$. 

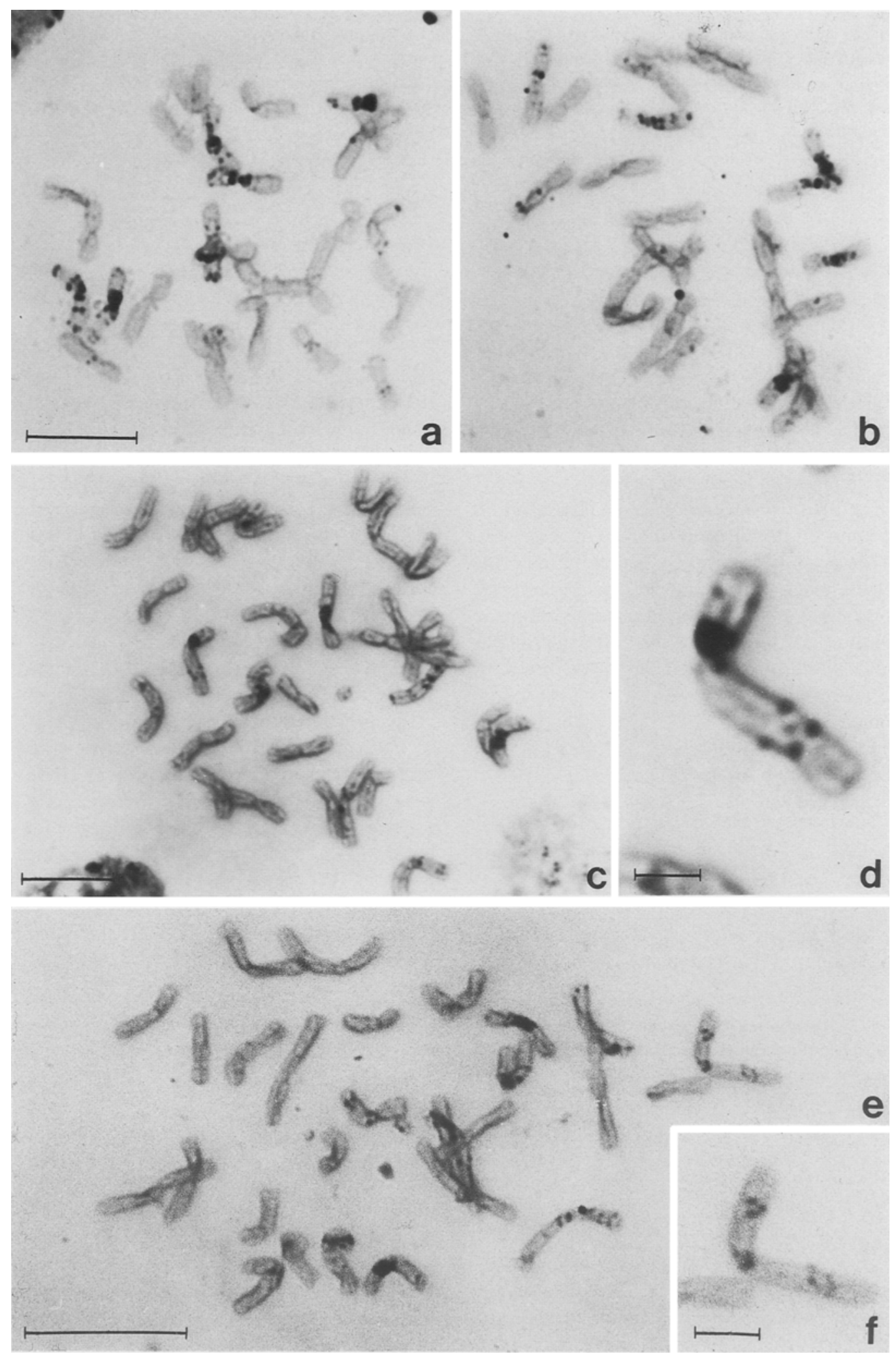
Figure 1. Phase contrast photographs of $\mathrm{N}$-banded metaphase complements from root tips of nullisomic 5B wheat-rye hybrids (Figures $1 \mathrm{a}$ and $1 \mathrm{~b}$ ), euploid hybrids (Figures $\mathrm{lc}$ and $1 \mathrm{~d}$ ) and hybrids monoisosomic for 5BL (Figures $1 \mathrm{e}$ and $1 \mathrm{f}$ ). Figures $1 \mathrm{a}$ and $\mathrm{b}$ show the complement of the two nullisomic 5B plants analyzed. Figures 1d and If show the $\mathrm{N}$-banded chromosome $5 \mathrm{~B}$ and the isochromosome for the long arm of $5 \mathrm{~B}$ at a higher magnification. (Figures $\mathrm{la}, 1 \mathrm{~b}, \mathrm{lc}, 1 \mathrm{l} ; \mathrm{Bar}=10 \mu \mathrm{m}$ ) (Figures $1 \mathrm{~d}, \mathrm{lf} ; \mathrm{Bar}=2 \mu \mathrm{m}$ )

\section{RESULTS}

\subsection{The chromosome complements of the hybrids}

A total of eight monosomic 5B wheat spikes were hand pollinated with rye pollen. Fifty-nine seeds were harvested which subsequently gave rise to 32 seedlings. The chromosome number of nineteen of these was counted and twelve of these plants were analyzed by $\mathrm{N}$-banding. Four different chromosome complements were identified in the twelve hybrids. Seven plants had 27 chromosomes, but only in two of these was chromosome 5B missing (Figures $1 \mathrm{a}$ and $1 \mathrm{~b}$ ). The remaining five plants all had 28 chromosomes, and of these three plants possessed chromosome 5B (Figures 1c and 1d) while in the other two chromosome $5 \mathrm{~B}$ had been replaced by an isochromosome for the long arm of chromosome 5B (Figures le and 1f). The nullisomic 5B hybrids, the euploid hybrids and the monoisosomic 5BL hybrids were thereafter selected for further study.

\subsection{Chiasma formation in the wheat-rye hybrids}

The squashed chromosome complements of microsporocytes at metaphase $I$ were analyzed in two hybrids nullisomic for 5B, two euploid hybrids and one hybrid monoisosomic for $5 \mathrm{BL}$ (Table I, Figure 2). In the nullisomic 5B hybrid, there was a mean number of 15.5 univalents (range 9-22), 4.5 bivalents (range 3-9), 0.7 trivalents (range 0-3) and 0.05 quadrivalents (range $0-1$ ), the mean number of chiasmata per cell being 6.93 . In the euploid hybrids the mean number of chiasmata was tenfold lower $(0.7$ chiasmata per cell), and the chiasmatic associations were almost exclusively in the form of rod bivalents. These frequencies are similar to those reported by RILEY (ref. 19, see Introduction). A further reduction in the number of chiasmata was found in the monoisosomic 5BL hybrids. The mean number of chiasmata per cell was 0.25 , but nearly all of these $(0.20$ chiasmata per cell) were between the two homologous/identical arms of the isochromosome and only a mean of 0.05 chiasmata per cell were between the other chromosomes of the complement. Hence, if excluding the chiasmata in the isochromosome the number of chiasmata is fourteen times lower in this genotype than in the euploid hybrid. It is considered likely that a ring univalent is formed in more than the recorded $20 \%$ of the cells, but only well defined examples of univalent rings were counted.

Table I. Number of chromosome configurations and number of chiasmata in hybrids between wheat and rye

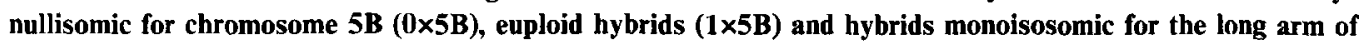
chromosome $5 B(2 \times 5 B L)$.

\begin{tabular}{|c|c|c|c|c|c|c|c|c|}
\hline \multirow{3}{*}{$\begin{array}{l}\text { Geno- } \\
\text { type }\end{array}$} & \multirow{3}{*}{$\begin{array}{l}\text { Plant } \\
\text { number }\end{array}$} & \multirow{3}{*}{$\begin{array}{l}\text { No. of } \\
\text { cells }\end{array}$} & \multirow{3}{*}{ I } & \multicolumn{4}{|c|}{ Chromosome configuration } & \multirow{3}{*}{$\begin{array}{l}\text { No. of } \\
\text { chiasmata }\end{array}$} \\
\hline & & & & & & III & IV & \\
\hline & & & & Rod & Ring & & & \\
\hline \multirow[t]{2}{*}{$0 \times 5 \mathrm{~B}$} & 1 & 24 & 15.63 & 4.13 & 0.46 & 0.63 & 0.08 & 6.54 \\
\hline & 2 & 32 & 15.38 & 3.47 & 1.06 & 0.81 & 0.03 & 7.31 \\
\hline \multirow[t]{2}{*}{$1 \times 5 \mathrm{~B}$} & 1 & 64 & 26.92 & 0.50 & 0.02 & 0.02 & --- & 0.58 \\
\hline & 2 & 61 & 26.36 & 0.82 & $-\ldots$ & --- & --- & 0.82 \\
\hline $2 \times 5 \mathrm{BL}$ & 1 & 75 & 27.69 & 0.05 & $0.20^{\mathrm{a}}$ & --- & --- & 0.25 \\
\hline
\end{tabular}

a) Univalent rings consisting of the isochromosomes for the long arm of chromosome $5 \mathrm{~B}$. 


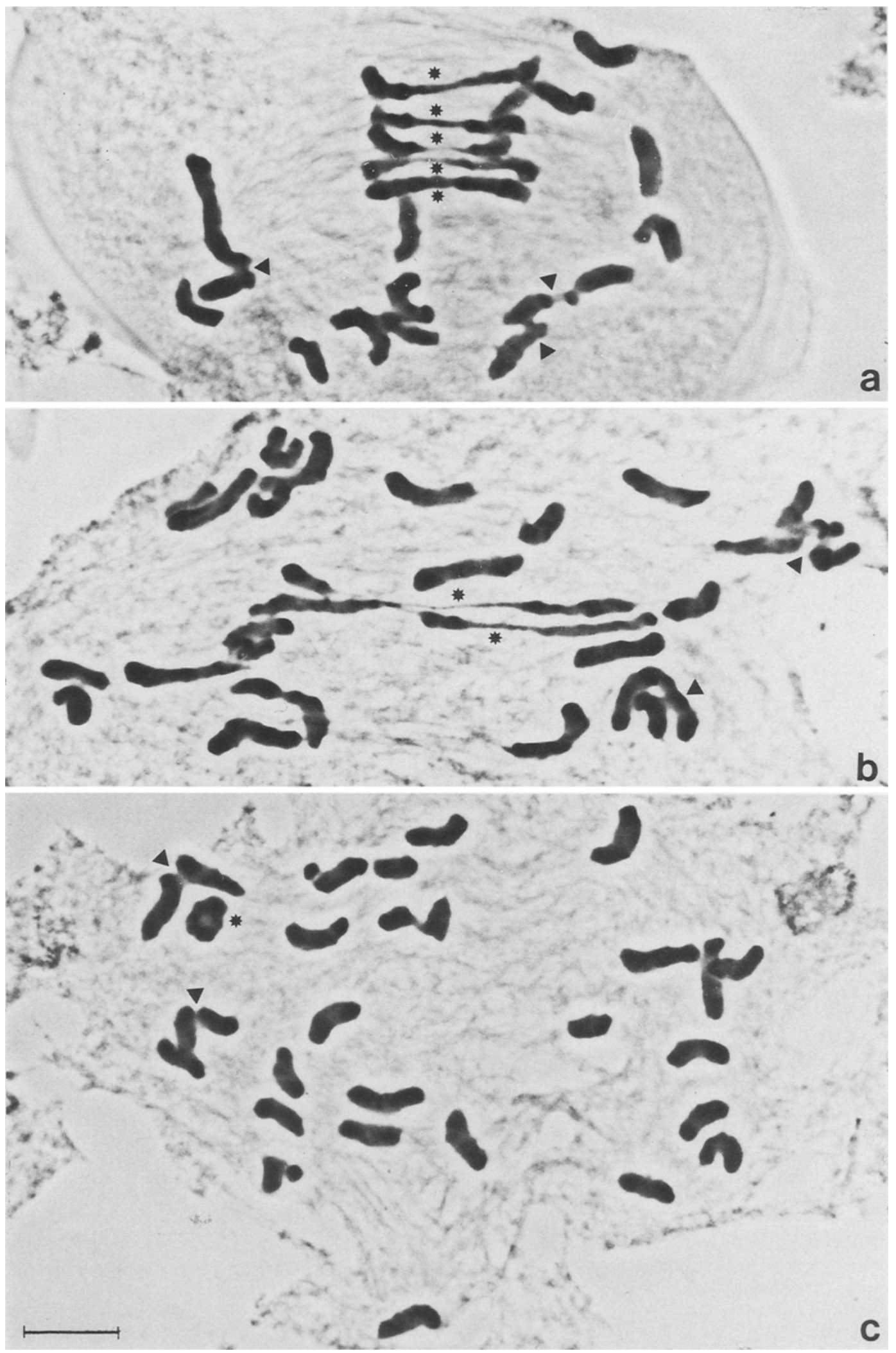


Figure 2. Phase contrast photographs of orcein stained metaphase I complements of a nullisomic 5B wheat-rye hybrid (Figure 2a), an euploid hybrid (Figure $2 b$ ) and a hybrid monoisosomic for 5BL (Figure 2c). In Figure 2a are seen five rod bivalents (asterisks) and in Figure $2 \mathrm{~b}$ two rod bivalents (asterisks) while the monoisosomic 5BL complement is achiasmatic with the exception of the chiasma formed between the two arms of the isochromosomes (asterisks). Note the nonchiasmatic association between several of the univalents in the three genotypes (arrowheads). (Bar $=10 \mu \mathrm{m}$ )

Table II. Synaptonemal complex (SC) length, degree of pairing, total lateral component (LC) length, types of multiple associations and the mean number of pairing partner exchanges per lateral component involved in synapsis at zygotene and early diplotene in wheat $\times$ rye hybrids nullisomic for chromosome $5 B$. EZ, early zygotene. MZ, mid zygotene. LZ, late zygotene. ED, early diplotene. MD, mid diplotene. ND, not determined. s.d., standard deviation.

\begin{tabular}{|c|c|c|c|c|c|}
\hline $\begin{array}{l}\text { Nucleus } \\
\text { number }\end{array}$ & $\begin{array}{l}\text { SC } \\
\text { length } \\
\mu \mathrm{m}\end{array}$ & $\begin{array}{l}\text { Total LC } \\
\text { length } \\
\mu \mathrm{m}\end{array}$ & $\begin{array}{l}\% \\
\text { pair- } \\
\text { ing }\end{array}$ & $\begin{array}{l}\text { Types of } \\
\text { associations }\end{array}$ & $\begin{array}{l}\text { Number of } \\
\text { pairing partner } \\
\text { exchanges } \\
\text { per LC }\end{array}$ \\
\hline $\mathrm{EZ1}$ & 123 & 3450 & 7 & $1 \times 25,1 \times 2$ & 2.04 \\
\hline $\mathrm{EZ2}$ & 171 & 4147 & 8 & ND & ND \\
\hline Mean \pm s.d. & 147 & 3799 & 8 & & 2.04 \\
\hline MZ1 & 128 & 3224 & 8 & $1 \times 28,3 \times 2$ & 0.94 \\
\hline MZ2 & 194 & 3593 & 11 & $1 \times 33,1 \times 2$ & 1.34 \\
\hline MZ3 & 208 & 3150 & 13 & ND & ND \\
\hline MZ4 & 236 & 3108 & 15 & ND & ND \\
\hline MZ5 & 271 & 3368 & 16 & ND & ND \\
\hline MZ6 & 304 & 3294 & 18 & ND & ND \\
\hline MZ7 & 278 & 3129 & 18 & $1 \times 25,1 \times 4,1 \times 3$ & 1.14 \\
\hline MZ8 & 314 & 2922 & 21 & ND & ND \\
\hline Mean \pm s.d. & $241 \pm 63$ & $3224 \pm 200$ & $15 \pm 4$ & & $1.14 \pm 0.20$ \\
\hline LZ1 & 154 & 3571 & 9 & $1 \times 15,1 \times 5,2 \times 2$ & 0.92 \\
\hline LZ2 & 151 & 3046 & 10 & $1 \times 31,1 \times 2$ & 1.30 \\
\hline LZ3 & 204 & 3284 & 12 & ND & ND \\
\hline LZ4 & 458 & 4062 & 23 & ND & ND \\
\hline LZ5 & 432 & 2782 & 31 & $1 \times 29,1 \times 4$ & 0.86 \\
\hline LZ6 & 468 & 2998 & 31 & $1 \times 26,1 \times 4,8 \times 2$ & ND \\
\hline LZ7 & 442 & 2811 & 31 & $1 \times 24,1 \times 4,4 \times 2$ & ND \\
\hline LZ8 & 716 & 4050 & 35 & $1 \times 29,1 \times 6,2 \times 2$ & 1.21 \\
\hline LZ9 & 657 & 2910 & 45 & ND & ND \\
\hline LZ10 & 651 & 2760 & 47 & ND & ND \\
\hline LZ1 1 & 925 & 2958 & 63 & ND & ND \\
\hline LZ12 & 936 & 2517 & 74 & ND & ND \\
\hline Mean \pm s.d. & $516 \pm 270$ & $3146 \pm 502$ & $34 \pm 20$ & & $1.07 \pm 0.22$ \\
\hline ED1 & 651 & 2759 & 47 & ND & ND \\
\hline ED2 & 573 & 2000 & 57 & ND & ND \\
\hline MD1 & 522 & 1374 & 76 & ND & ND \\
\hline Mean \pm s.d. & $582 \pm 65$ & $2044 \pm 694$ & $60 \pm 15$ & & \\
\hline
\end{tabular}

Figure 3. A montage of micrographs of a spread, late zygotene nucleus from a wheat-rye hybrid nullisomic for $5 \mathbf{B}$ (LZ6, 31\% pairing). (Bar $=10 \mu \mathrm{m})$ 


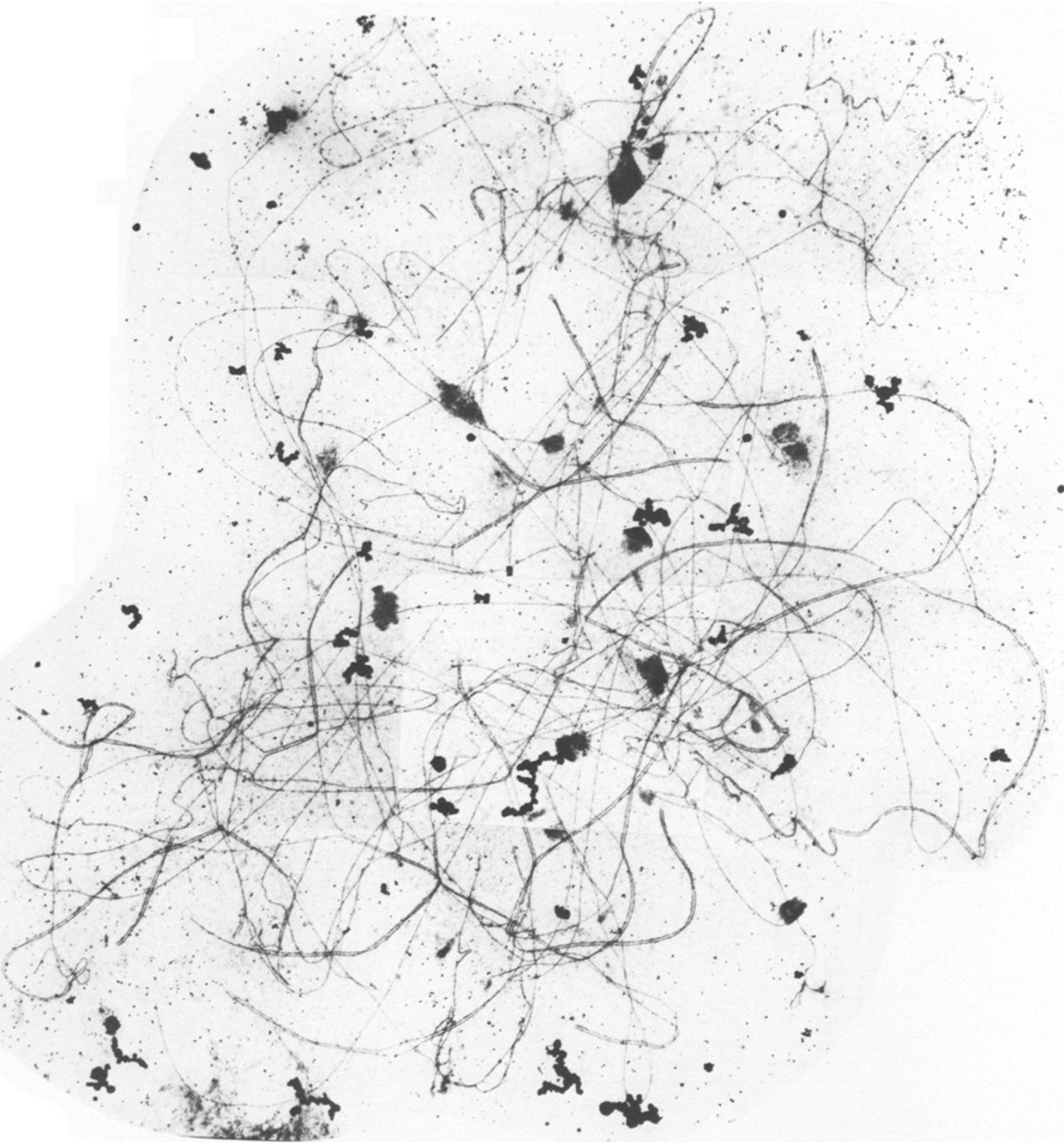



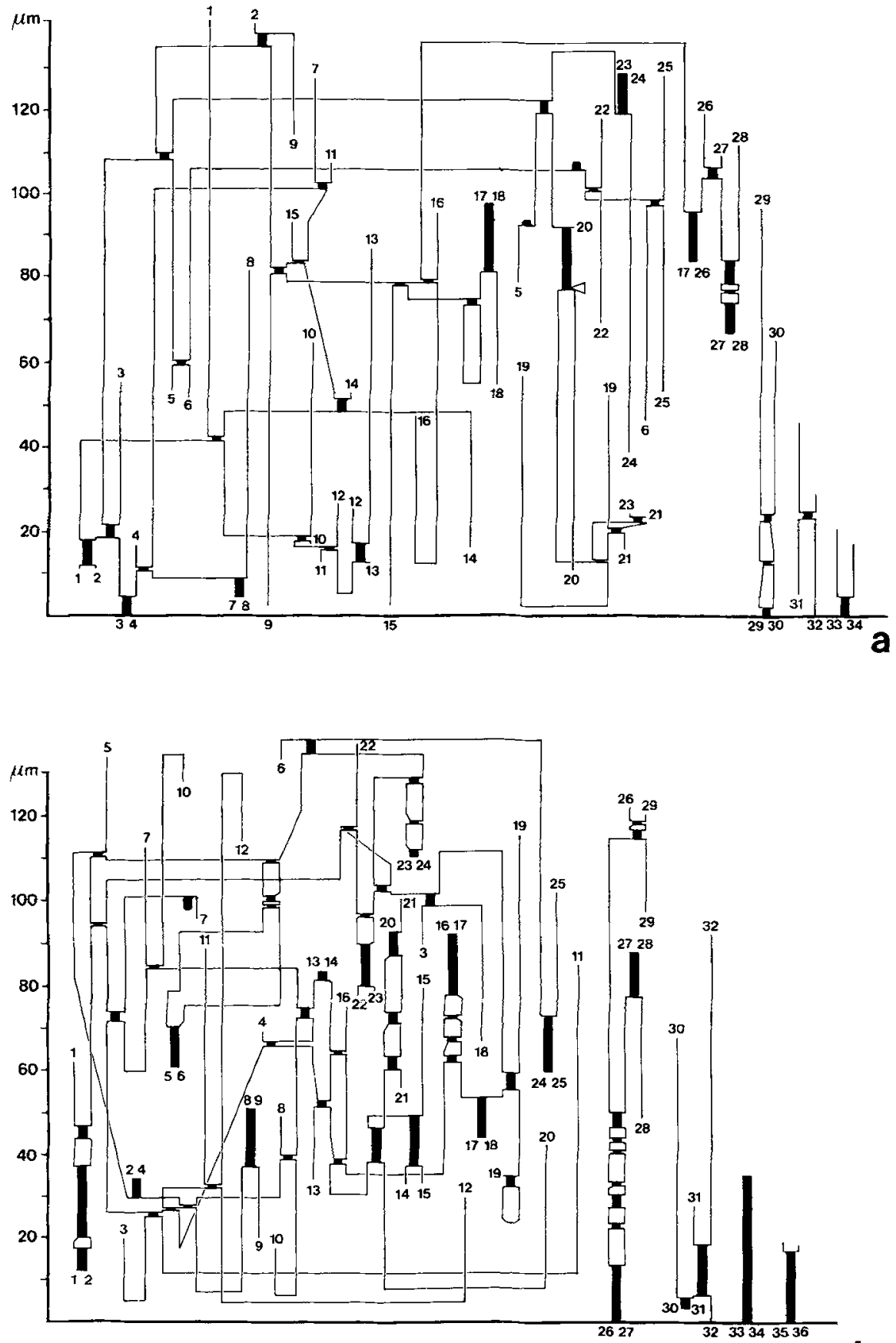

b

Figure 4. Idiograms of the lateral component complement of two mid zygotene nuclei (Figure 4a, MZ1, 8\% pairing and Figure $4 b, M Z 7,18 \%$ pairing) and a late zygotene nucleus (Figure $4 \mathrm{c}, \mathrm{LZ8}, 35 \%$ pairing) from nullisomic $5 \mathrm{~B}$ hybrids. The lateral components are shown as lines, denoted by numbers, and synaptonemal complexes are shown as black areas combining lateral components. Lateral components or lateral component fragments which are unpaired throughout their length are not included. The actual lengths of the lateral components are represented by the vertical lines only. 


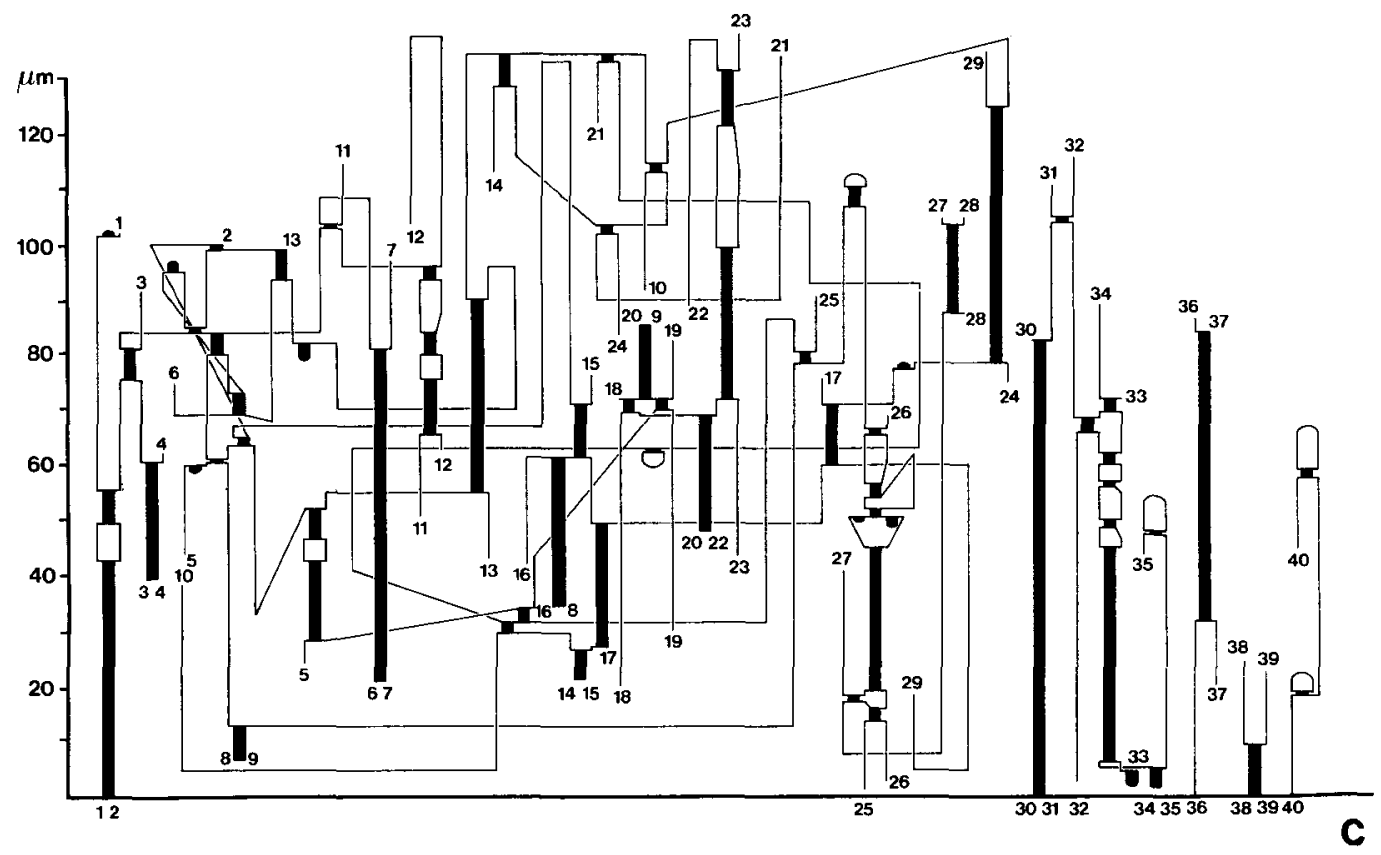

In all three genotypes several nonchiasmatic connections between univalents were observed in the form of faintly stained connections between chromosomes (Figure 2). It is conceivable that these associations result from previous synaptonemal complex formation between chromosomes, where incomplete elimination of the synaptonemal complex or association between the chromatin of the synapsed chromosomes account for the formation of these nonchiasmatic associations. It was not attempted to identify and discriminate between the chromosomes of the rye genome and those belonging to the wheat genomes.

\subsection{Synapsis in nullisomic $5 B$ hybrids}

A total of 25 spread nuclei, ranging in stage from early zygotene to mid diplotene, were analyzed from the wheat-rye hybrids nullisomic for chromosome 5B (Table II). The zygotene stage was subdivided into early, mid and late zygotene on the basis of nuclear morphology. The early zygotene stage was characterized by a distinct bouquet due to a close association of the telomeres while at late zygotene the bouquet is hardly recognizable (Figure 3). Nuclei with an intermediate morphology were assigned to the mid zygotene stage. The early diplotene stage was characterized by the initiation of synaptonemal complex degradation while nuclei showing more pronounced degradation of the synaptonemal complexes and lateral components were classified as nuclei of mid diplotene.

The substaging of zygotene on the basis of morphology only correlated to some degree with the extent of synaptonemal complex formation. This is in particular the case at late zygotene where the pairing percentage varied from $9 \%$ to $74 \%$ with a mean of $34 \%$. The large variation in synapsis between nuclei assigned to the late zygotene stage may result from an incorrect staging of the less synapsed nuclei, but since the morphological characteristics of the zygotene nuclei were the same, the variation in the degree of synapsis is more likely a normal phenomenon in this genotype.

The synaptic configurations were analyzed in detail in one early zygotene, three mid zygotene 


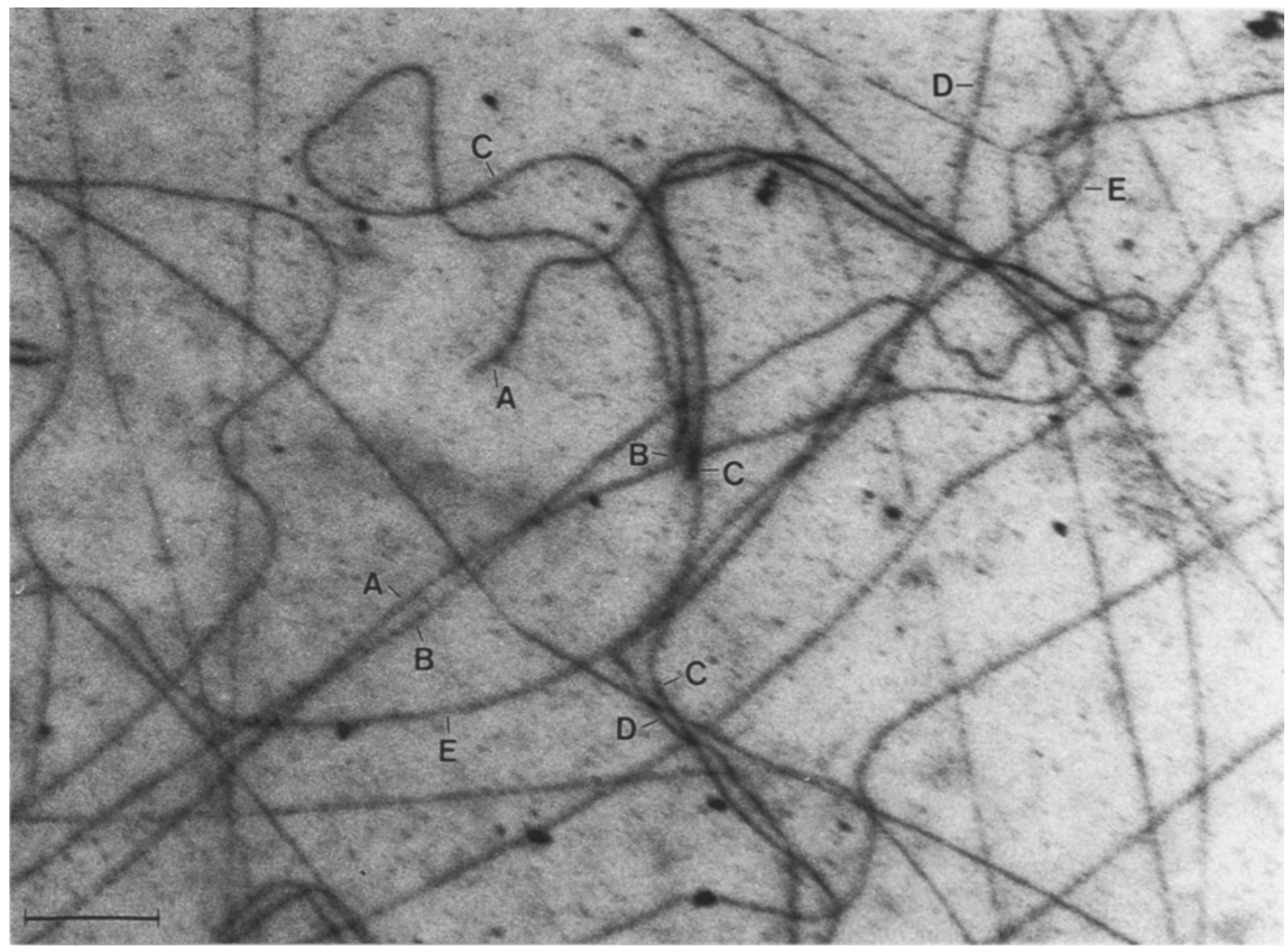

Figure 5. Electron micrograph of pairing partner exchange in wheat-rye hybrids nullisomic for $5 \mathrm{~B}$. The lateral components exchanging partners are denoted by capital letters. $($ Bar $=1 \mu \mathrm{m})$

and six late zygotene nuclei (Table II). In the early zygotene nucleus all the 27 lateral components were traceable throughout their length and had all engaged in synapsis, the pairing percentage being $7 \%$. A total of 55 synaptonemal complex segments were detected, of these 9 were telomeric, 42 interstitial and 4 segments combined lateral components which had folded back on themselves. Extensive pairing partner exchange had occurred, and nearly all lateral components of this nucleus ( 25 out of 27 ) were involved in the same multiple association. On the average each lateral component had about three pairing partners, the mean number of pairing partner exchanges being 2.04 .

Idiograms of two mid zygotene nuclei with $8 \%$ and $18 \%$ synapsis are shown in Figures $4 a$ and $4 \mathrm{~b}$. The synaptic configurations were essentially the same in the two nuclei and similar to that observed at early zygotene. In both nuclei 46 lateral components or lateral component fragments were found. Of these 34 and 36 had synapsed with other lateral components forming an association of 28 lateral components in the nucleus with $8 \%$ synapsis and 29 in the nucleus with $18 \%$ synapsis. The mean number of pairing partner exchanges per lateral component engaged in synapsis was. 1.14. As at the early zygotene stage the synaptonemal complex segments had primarily formed interstitially ( 29 and 46 segments), 9 and 14 segments were telomeric while three and two represented foldback pairing.

In the six traced late zygotene nuclei the number of lateral components or lateral component fragments ranged from 33 to 50 . As was the case at the preceding stages there was extensive pairing partner exchange (Figures $4 \mathrm{c}$ and 5) and 
Table III. Synaptonemal complex (SC) length, degree of pairing, total lateral component (LC) length, types of multiple associations and the mean number of pairing partner exchanges per lateral component involved in synapsis at zygotene and early diplotene in euploid wheatxrye hybrids. EZ, early zygotene. MZ, mid zygotene. LZ, late zygotene. ED, early diplotene. s.d., standard deviation. ND, not determined.

\begin{tabular}{|c|c|c|c|c|c|}
\hline $\begin{array}{l}\text { Nucleus } \\
\text { number }\end{array}$ & $\begin{array}{l}\text { SC } \\
\text { length } \\
\mu \mathrm{m}\end{array}$ & $\begin{array}{l}\text { Total LC } \\
\text { length } \\
\mu \mathrm{m}\end{array}$ & $\begin{array}{l}\% \\
\text { pair- } \\
\text { ing }\end{array}$ & $\begin{array}{l}\text { Types of } \\
\text { associations }\end{array}$ & $\begin{array}{l}\text { Number of } \\
\text { pairing partner } \\
\text { exchanges } \\
\text { per } L C\end{array}$ \\
\hline $\mathrm{EZl}$ & 143 & 3082 & 9 & $1 \times 26,2 \times 3,1 \times 2$ & 0.94 \\
\hline $\mathrm{EZ2}$ & 183 & 2710 & 14 & $\mathrm{ND}$ & ND \\
\hline EZ3 & 207 & 2744 & 15 & $1 \times 20,1 \times 3,2 \times 2$ & 0.84 \\
\hline Mean \pm s.d. & $178 \pm 32$ & $2845 \pm 206$ & $13 \pm 3$ & & 0.89 \\
\hline $\mathrm{MZl}$ & 313 & 2842 & 22 & $1 \times 19,1 \times 5,1 \times 3,3 \times 2$ & 0.65 \\
\hline $\mathrm{MZ2}$ & 488 & 2495 & 39 & $1 \times 26,1 \times 3,1 \times 2$ & 0.97 \\
\hline Mean $\pm s . d$ & 401 & 2669 & 31 & & 0.81 \\
\hline $\mathrm{LZ1}$ & 603 & 3670 & 33 & $1 \times 8,1 \times 5,2 \times 4,7 \times 2$ & 0.39 \\
\hline $\mathrm{LZ2}$ & 827 & 3193 & 52 & $1 \times 10,1 \times 5,2 \times 4,4 \times 3,7 \times 2$ & 0.55 \\
\hline Mean \pm s.d. & 715 & 3432 & 43 & & 0.47 \\
\hline ED1 & 216 & 2924 & 17 & ND & ND \\
\hline ED2 & 254 & 2824 & 18 & ND & ND \\
\hline ED3 & 357 & 3124 & 23 & ND & ND \\
\hline ED4 & 566 & 3730 & 30 & ND & ND \\
\hline ED5 & 583 & 3758 & 31 & ND & ND \\
\hline ED6 & 513 & 3106 & 33 & ND & ND \\
\hline ED7 & 649 & 3170 & 41 & ND & ND \\
\hline ED8 & 567 & 2430 & 47 & ND & ND \\
\hline ED9 & 712 & 2834 & 50 & ND & ND \\
\hline Mean $\pm s . d$ & $491 \pm 175$ & $3100 \pm 428$ & $32 \pm 12$ & & \\
\hline
\end{tabular}

most lateral components in each nucleus had synapsed into a single multiple association, the mean number of pairing partner exchanges per lateral component engaged in synapsis being 1.07. The distribution of the synaptonemal complex segments in the complements was also very similar to that seen at the previous stages as exemplified by nucleus LZ8 (Figure 4c, 35\% pairing) where 11 of the 69 synaptonemal complex segments involved the telomeres while 46 had formed interstitially. There was, however, an increase in the number of foldback paired regions ( 12 in nucleus $\mathbf{L Z 8}$ ).

The combined length of the four genomes is at early, mid and late zygotene $3799 \mu \mathrm{m}, 3224$ $\mu \mathrm{m}$ and $3146 \mu \mathrm{m}$. At mid zygotene the combined length of the three genomes of allohexaploid wheat amounts to $2063 \mu \mathrm{m}(9)$ and $2116 \mu \mathrm{m}$ in haploid wheat at mid-late zygotene (25), while the rye genome at mid zygotene is 6-700 $\mu \mathrm{m}$ long (8), i.e. about a third of the wheat complement length. The combined lateral com-

Figure 6. A montage of micrographs of a spread, mid zygotene nucleus from a euploid wheat-rye hybrid (MZ1, $22 \%$ pairing). (Bar $=10 \mu \mathrm{m})$ 


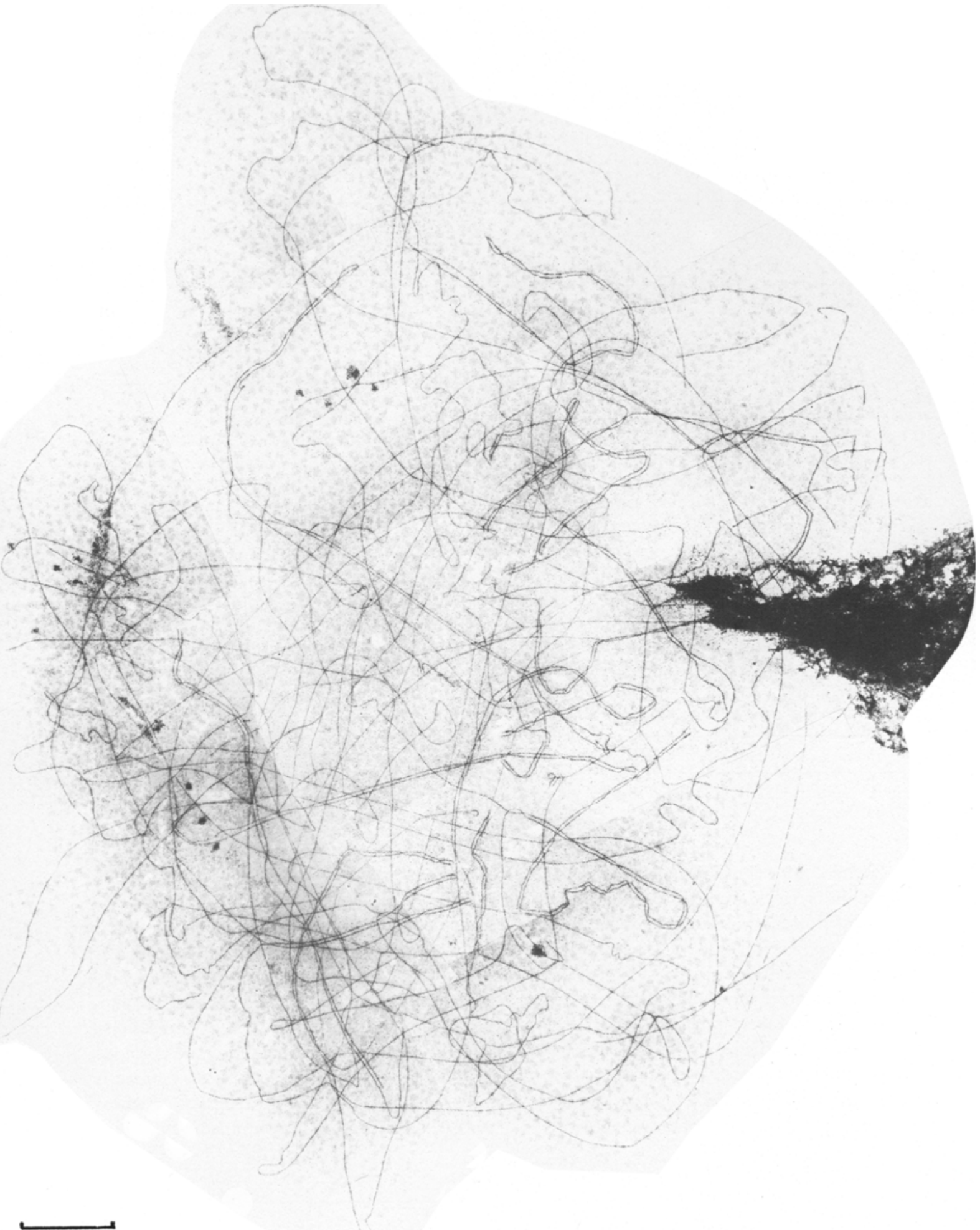


ponents length of the nullisomic 5B hybrid is thus slightly higher than expected from the separate data for rye and wheat. However, as the complement length in the spreads is highly dependent on the spreading conditions and therefore quite variable (Table II), the significance of these possible differences is uncertain.

An identification of the individual lateral components or an assignment to the rye genome or the wheat genomes was not attempted. As noted above the combined length of the seven rye chromosomes is roughly one third of the length of the wheat complement, i.e. comparable to the length of one wheat genome and a classification by length of the individual lateral components is therefore not possible. Some lateral components possessed knob-like structures at the telomeres, possibly signifying the distal heterochromatin of the rye chromosomes, but their erratic presence as well as the occasional occurrence of distal knobs on the wheat lateral components (9) obviated the use of these potential marker structures for the identification of the two complements.

At early and mid diplotene the synaptonemal complex degradation appeared to proceed as described in detail for haploid wheat (25), where degradation is initiated at a number of locations along the synaptonemal complexes and unpaired lateral components, generating distinct fragments which subsequently are degraded primarily from the ends. In the two early diplotene nuclei $52 \%$ of the complement had synapsed.

\subsection{Synapsis in euploid hybrids}

Sixteen nuclei, ranging in stage from early zygotene to early diplotene, were analyzed from the euploid wheat-rye hybrids (Table III). Of these six nuclei, two from each of the three zygotene substages were traced. The ultrastructural characteristics of the zygotene and diplotene nuclei were basically the same as in the nullisomic 5B hybrids (Figure 6), the only possible exception being that the bouquet configuration in the euploid hybrids was more distinct and appeared to be retained for a longer time into mid zygotene than seen in the nullisomic $5 \mathrm{~B}$ hybrids.

Idiograms of three spread nuclei, one from each of the three zygotene substages are shown in Figures $7 \mathrm{a}, 7 \mathrm{~b}$ and $7 \mathrm{c}$. In the six traced nuclei the number of lateral components or lateral component fragments ranged from 33 to 50 of which most had engaged in synapsis. At early zygotene (mean of $13 \%$ pairing), multiple associations of 26 and 20 lateral components had formed, the mean number of pairing partner exchanges per lateral component engaged in synapsis being 0.89 (Table III, Figure 8 ). At mid zygotene (mean of $31 \%$ pairing) similar results are obtained with respect to the number of lateral components in the multiple associations and the number of pairing partner exchanges. Prominent changes were, however, observed at late zygotene where the multiple associations were considerably less complex than at the preceding stages, the mean number of pairing partner exchanges per lateral component engaged in synapsis being 0.47 , i.e. about half of that found at the earlier stages. At all three stages the number of pairing partner exchanges per lateral component was lower than in the nullisomic $5 \mathrm{~B}$ hybrids and at early and late zygotene the lateral components had less than half the number of pairing partner exchanges observed in the nullisomic 5B hybrids. This difference between the two genotypes is also apparent when comparing the length and distribution of synaptonemal complexes in the two genotypes (see Figures 4 and 7). In the euploid hybrids long synaptonemal complexes had formed from the telomeres of pairs of lateral components with relatively short interstitial segments of synaptonemal complex between other combinations of lateral components, while interstitial synapsis with longer segments of synaptonemal complex appears to be more prominent in the nullisomic 5B hybrids.

Nine early diplotene nuclei of the euploid hybrids were analyzed. In these the mean degree of synapsis achieved amounted to $32 \%$ with a range from $17 \%$ to $50 \%$.

\subsection{Synapsis in monoisosomic 5BL hybrids}

The analysis of the wheat-rye hybrids carrying the isochromosome for the long arm of chromosome $5 \mathrm{~B}$ comprised a study of six mid zygotene nuclei, six late zygotene nuclei and four early- 
X. WANG \& P.B. Holm: Synapsis in wheat-rye hybrids

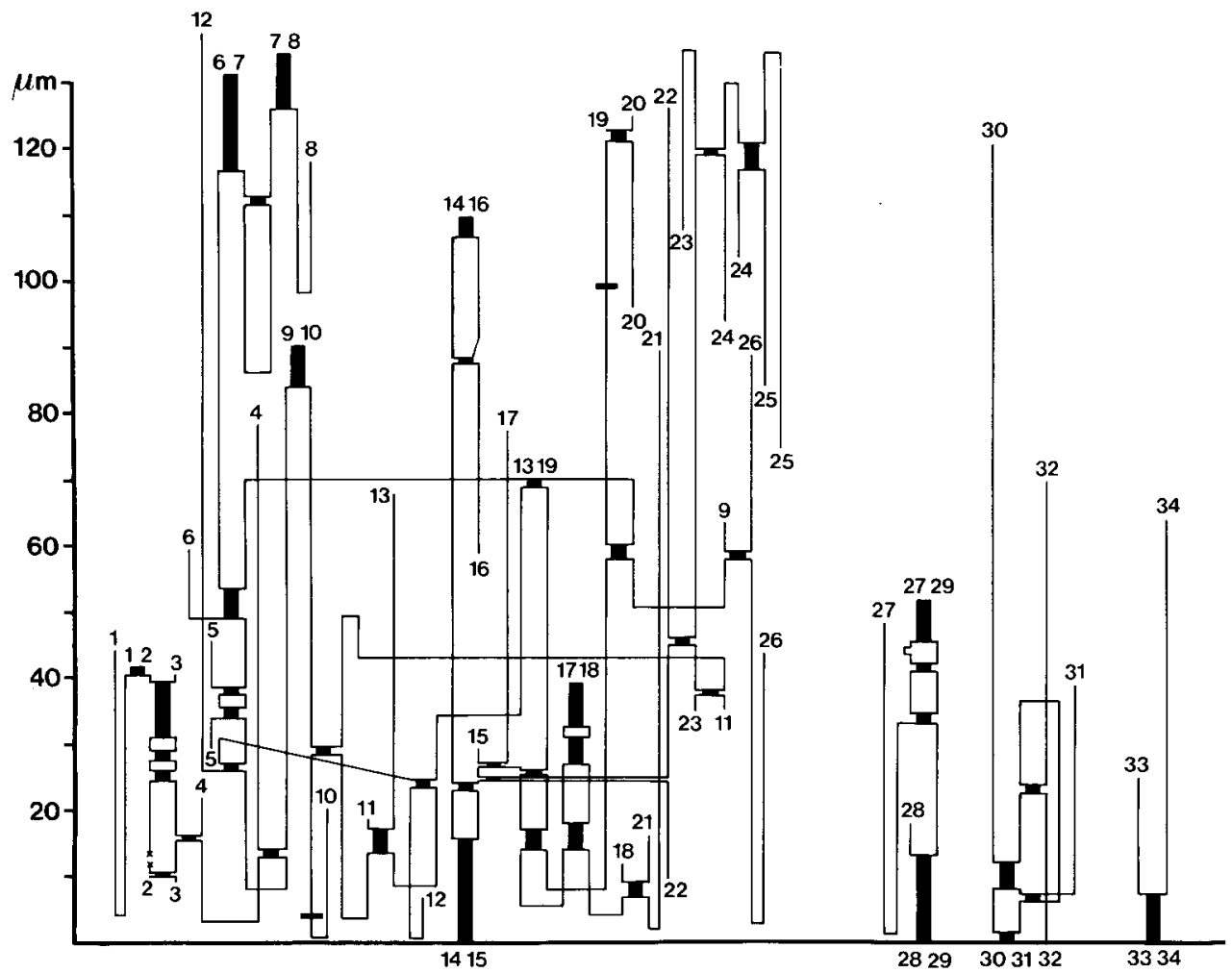

a

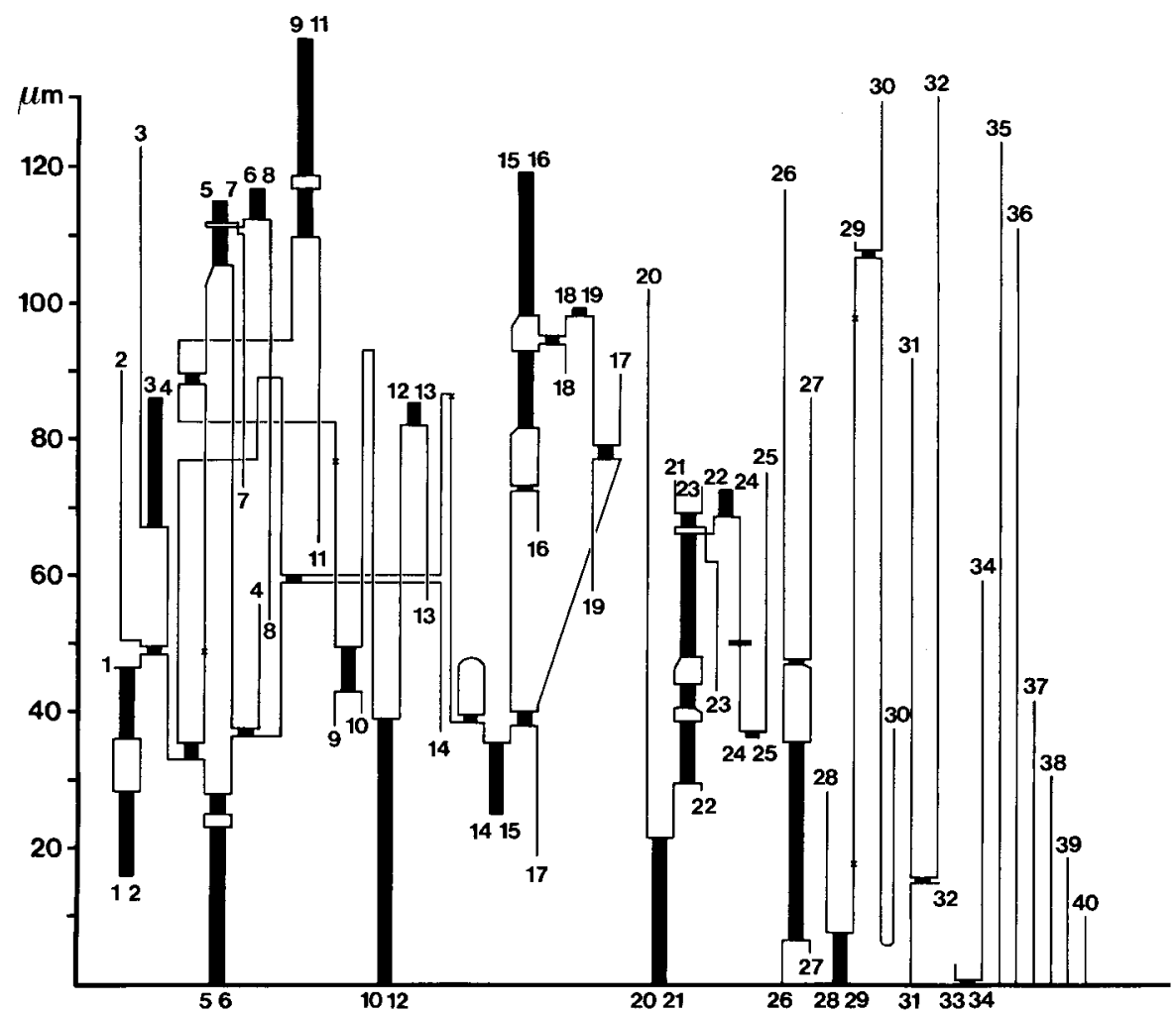


X. WANG \& P.B. Holm: Synapsis in wheat-rye hybrids

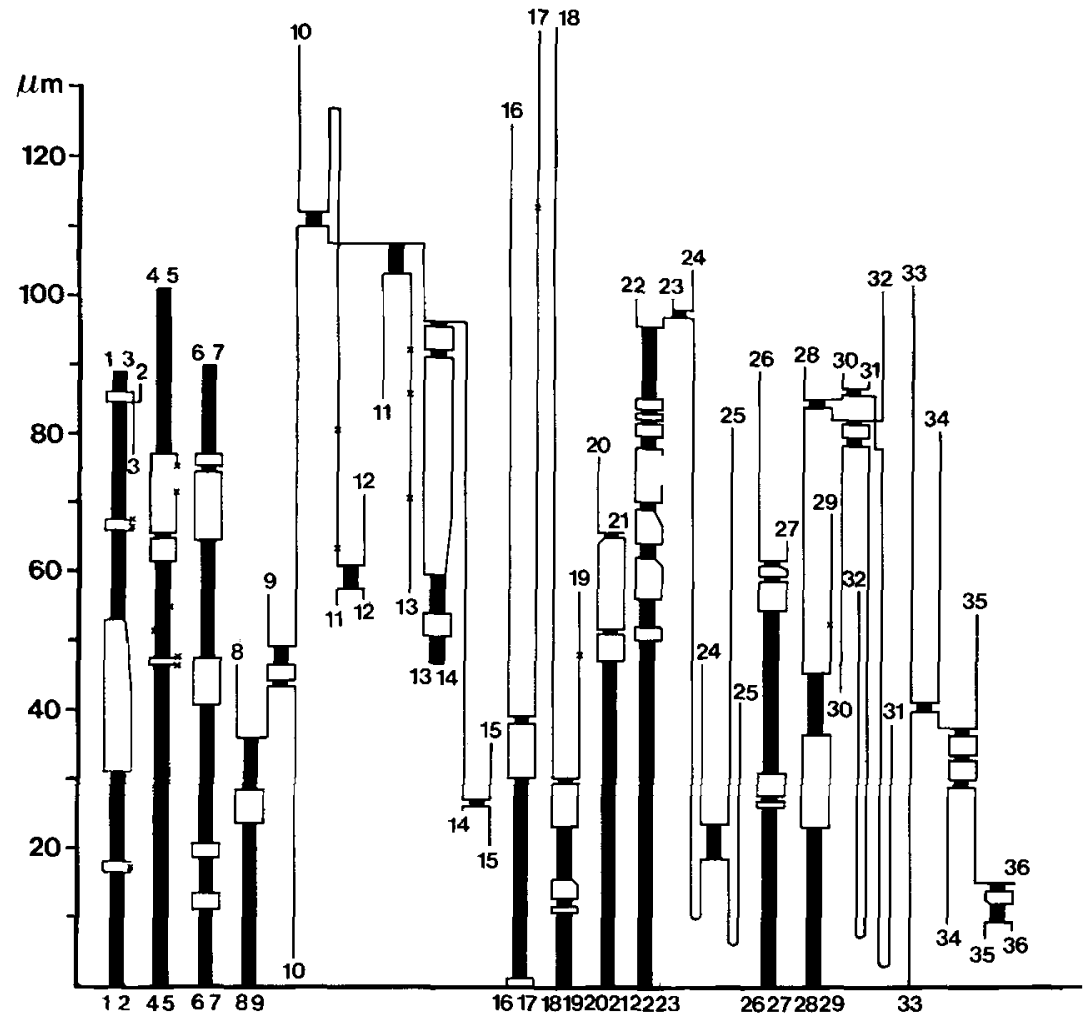

Figure 7. Idiograms of the lateral component complement of an early zygotene nucleus (Figure 7a, EZ1, 9\% pairing), a mid zygotene nucleus (Figure 7b, MZl, 22\% pairing) and a late zygotene nucleus (Figure 7c, LZ1, 33\% pairing) from euploid wheat-rye hybrids. For explanation of symbols see legend to Figure 4.

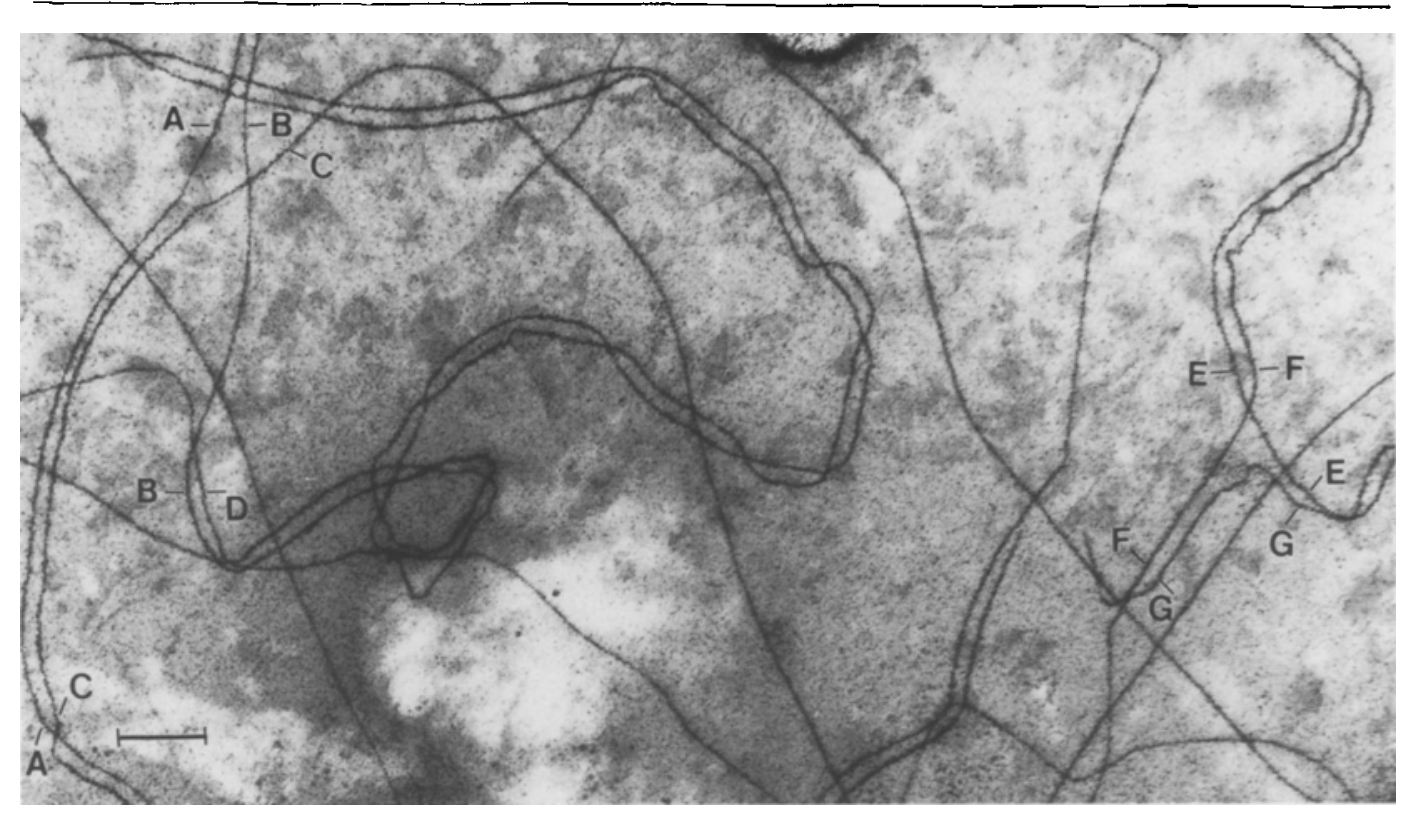

Figure 8. Electron micrograph of pairing partner exchanges in a spread nucleus of a euploid wheat-rye hybrid. The lateral components exchanging partners are denoted by capital letters. (Bar $=1 \mu \mathrm{m}$ ) 


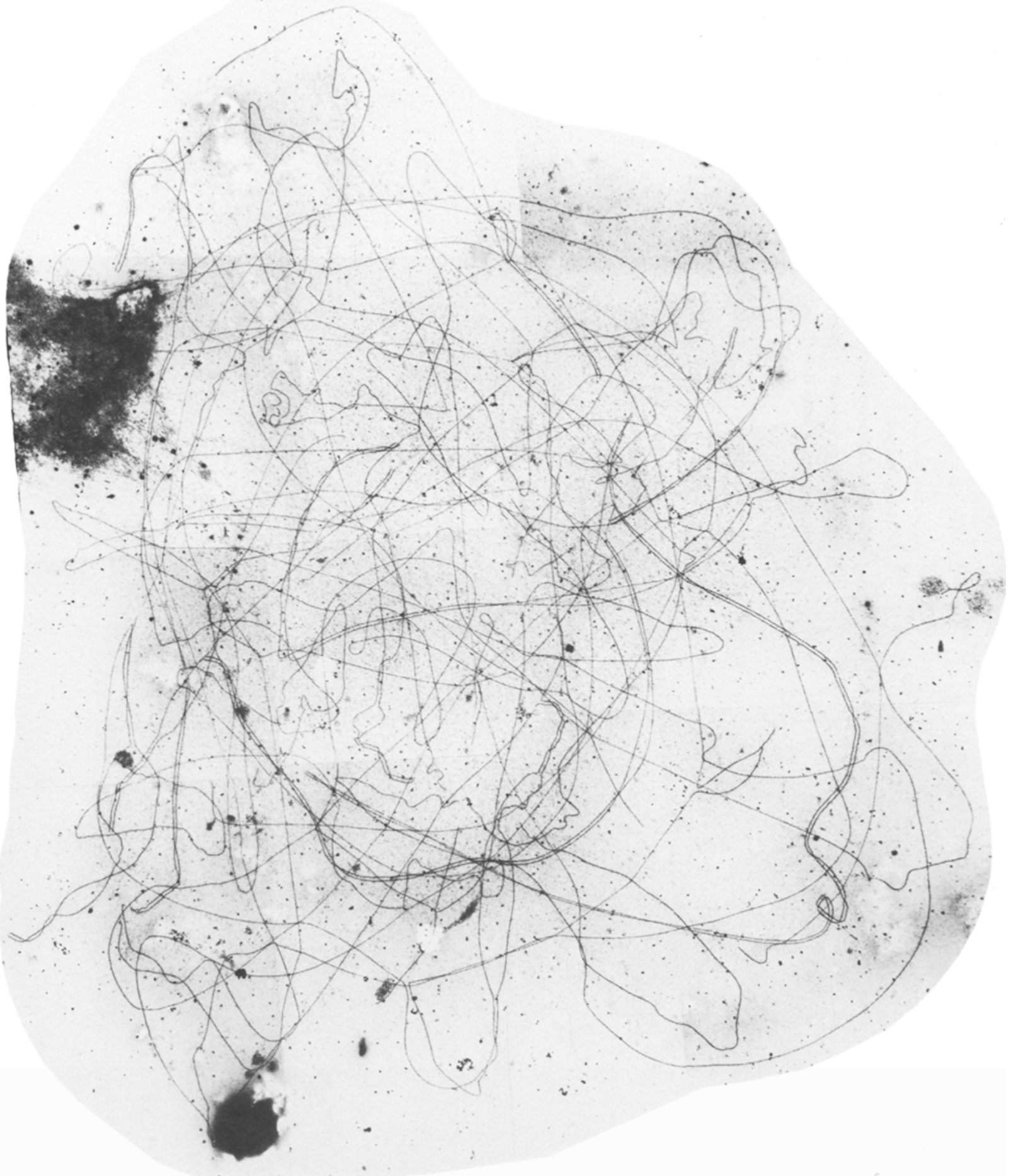


Table IV. Synaptonemal complex (SC) length, degree of pairing, total lateral component (LC) length, types of multiple associations and the mean number of pairing partner exchanges per lateral component involved in synapsis at zygotene and diplotene in wheat $\times$ rye hybrids monoisosomic for the long arm of chromosome 5B. EZ, early zygotene. MZ, mid zygotene. LZ, late zygotene. ED, early diplotene. MD, mid diplotene. s.d., standard deviation. ND, not determined.

\begin{tabular}{llllll}
\hline $\begin{array}{l}\text { Nucleus } \\
\text { number }\end{array}$ & $\begin{array}{l}\text { SC } \\
\text { length } \\
\mu \mathrm{m}\end{array}$ & $\begin{array}{l}\text { Total LC } \\
\text { length } \\
\mu \mathrm{m}\end{array}$ & $\begin{array}{l}\% \\
\text { pair- } \\
\text { ing }\end{array}$ & $\begin{array}{l}\text { Types of } \\
\text { associations }\end{array}$ & $\begin{array}{l}\text { Number of } \\
\text { pairing partner } \\
\text { exchanges } \\
\text { per LC }\end{array}$ \\
\hline MZ1 & 198 & 2642 & 15 & $1 \times 12,1 \times 5,1 \times 4,2 \times 2$ & 0.84 \\
MZ2 & 349 & 3302 & 21 & $1 \times 19,4 \times 2$ & 0.79 \\
MZ3 & 269 & 2436 & 22 & $1 \times 27$ & 1.81 \\
MZ4 & 524 & 3435 & 31 & $1 \times 22,4 \times 2$ & 1.30 \\
MZ5 & 507 & 2678 & 38 & ND & ND \\
MZ6 & 495 & 2231 & 44 & ND & ND \\
\hline Mean \pm s.d & $390 \pm 138$ & $2790 \pm 477$ & $29 \pm 11$ & & $1.19 \pm 48$ \\
\hline LZ1 & 260 & 2897 & 18 & $1 \times 15,1 \times 5,1 \times 4$ & 0.70 \\
LZ2 & 480 & 3292 & 29 & $1 \times 16,3 \times 3,3 \times 2$ & 0.78 \\
LZ3 & 426 & 2635 & 32 & $1 \times 10,4 \pm 3,12 \times 2$ & 0.24 \\
LZ4 & 636 & 3667 & 35 & ND & ND \\
LZ5 & 647 & 3383 & 38 & $1 \pm 20,1 \times 4,3 \times 2$ & 0.97 \\
LZ6 & 539 & 2591 & 42 & $1 \times 18,1 \times 4,1 \times 3,5 \times 2$ & 0.44 \\
\hline Mean \pm s.d. & $498 \pm 145$ & $3078 \pm 436$ & $32 \pm 8$ & & $0.63 \pm 0.29$ \\
\hline ED1 & 589 & 2260 & 52 & $1 \times 6,1 \times 4,4 \times 3,12 \times 2$ & ND \\
E-MD1 & 507 & 2281 & 45 & $2 \times 3,24 \times 2$ & ND \\
E-MD2 & 520 & 1803 & 58 & $2 \times 4,4 \times 3,20 \times 2$ & ND \\
E-MD3 & 696 & 2005 & 69 & $1 \times 4,2 \times 3,36 \times 2$ & ND \\
\hline Mean \pm s.d. & $578 \pm 87$ & $2088 \pm 227$ & $56 \pm 10$ & & \\
\hline & & & & & \\
\hline
\end{tabular}

mid diplotene nuclei. Nuclei at early zygotene were not identified in the spreads. Of these nuclei four mid zygotene and five late zygotene nuclei were analyzed in detail by a tracing of their lateral components and synaptonemal complexes. The zygotene stage appeared to progress as in the euploid hybrids and no differences between the fine structure of the spread nuclei from the two genotypes were encountered (Figures 6 and 9).

The number of lateral components or lateral component fragments in the six nuclei traced ranged from 30 to 36 . As in the other two genotypes multiple associations involving up to 27 lateral components or lateral component fragments form at mid zygotene, the mean number of pairing partner exchanges per lateral component involved in synapsis being 1.19 (Table IV, Figures 10, 11 a and $11 \mathrm{~b}$ ). The number of pairing partner exchanges per lateral components are virtually the same as found in the nullisomic $5 \mathrm{~B}$ hybrids, but about $50 \%$ higher than in the euploid hybrids (Table V). At late zygotene, however, the multiple associations

Figure 9. A montage of micrographs of a spread late zygotene nucleus ( $\mathrm{LZ1}, 18 \%$ pairing) from a wheat-rye hybrid monoisosomic for $5 \mathrm{BL}$. The isochromosome, which forms a completely paired hairpin, is denoted by arrows. $(\mathrm{Bar}=10 \mu \mathrm{m})$ 


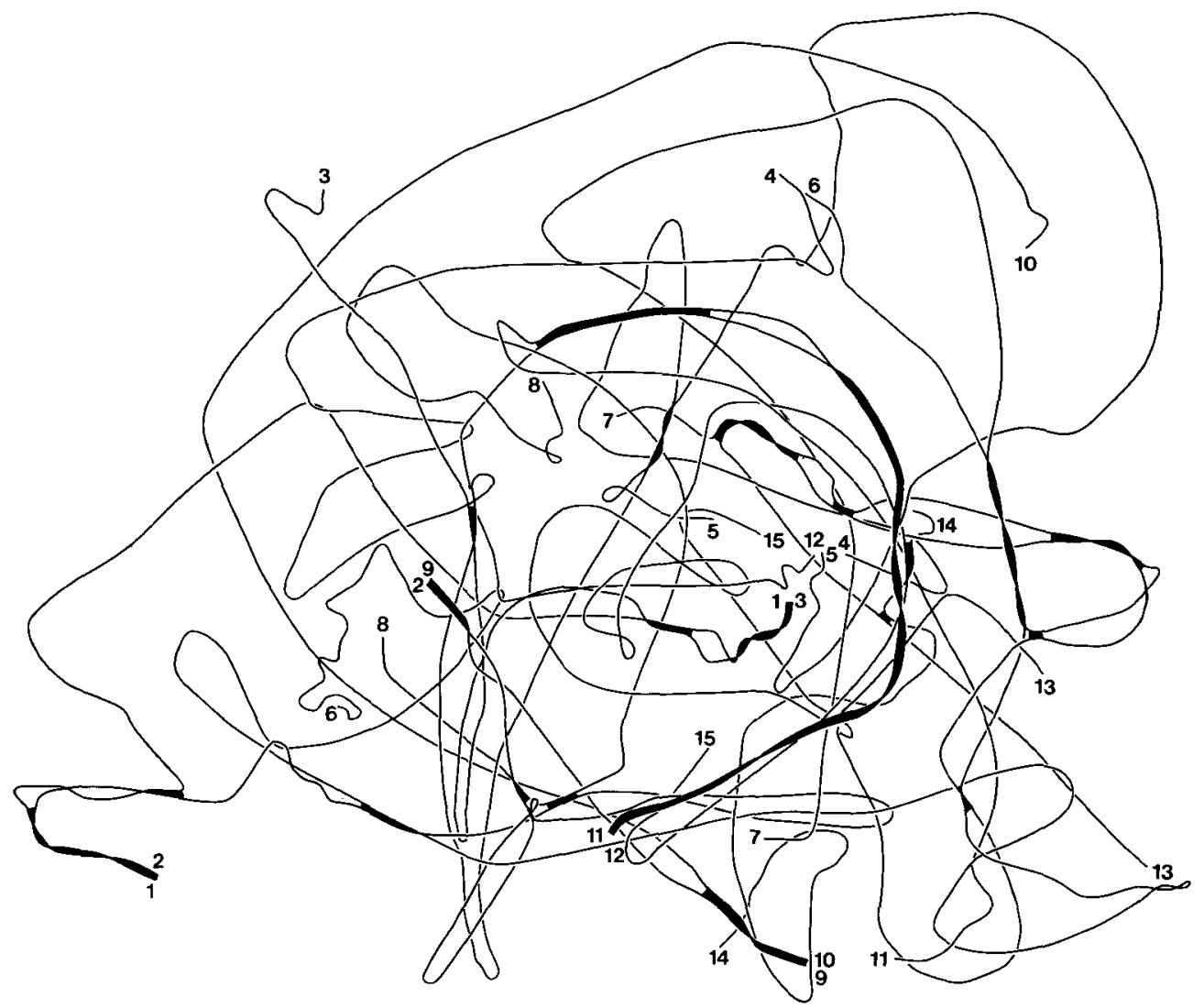

Figure 10. A tracing of a multiple association from a wheat-rye hybrid, monoisosomic for $5 \mathrm{BL}$ ( $\mathrm{LZ1}, 18 \%$ pairing). The association involves 15 lateral components or lateral component fragments, see also the idiogram in Figure $12 \mathrm{c}$.

were less complex, the mean frequency of pairing partner exchanges per lateral component involved in synapsis being 0.63 (Table IV, Figure $11 \mathrm{c})$. This number is only slightly higher than the number of 0.47 observed in the euploid hybrids, while the number in the nullisomic 5B hybrids at the same stage of development is nearly twice as high (1.07 pairing partner exchanges per lateral component, Table V). Furthermore, as is also the case for euploid wheat at late zygotene, primarily distal segments had synapsed with long synaptonemal complexes extending from the telomeres while the interstitial synaptonemal complex segments are short.

The initiation and progression of synaptonemal complex and lateral component degrada- tion at diplotene appeared to be the same as in trihaploid wheat (25) and the two other hybrid genotypes. In these nuclei several pairing partner exchanges were easily recognized even at an advanced stage of degradation (Table IV). In the four nuclei a mean of $56 \%$ of the complement had synapsed.

The isochromosome for the long arm of chromosome 5B was identified in one of the mid zygotene nuclei (MZ2, 21\% synapsis), in four late zygotene nuclei (LZ1, 18\%; LZ2, 29\%; LZ5, $38 \%$; LZ6, $42 \%$ synapsis) and in the early to mid diplotene nuclei E-MD1 and 2. In all of these nuclei the isochromosome folds back and synapses with itself forming a large hairpin. The lengths of the lateral component of the isochro- 
mosome were very constant in the five zygotene nuclei, being $134,148,129,130$ and $128 \mu \mathrm{m}$. In five of the seven nuclei analyzed synapsis was complete in the isochromosome (Figure 12) while in nuclei MZ2 and LZ2, $82 \%$ and $90 \%$ had synapsed, the unpaired part being the proximal part of the isochromosome. Hence, synaptonemal complex formation in the isochromosome was complete or nearly so in nuclei where only $18 \%$ to $42 \%$ of the complement had synapsed.

\section{DISCUSSION}

The following main conclusions on chromosome pairing and chiasma formation can be drawn from the present investigation of nullisomic 5B wheat-rye hybrids, euploid hybrids and hybrids where chromosome $5 \mathrm{~B}$ had been replaced by an isochromosome for the long arm of chromosome 5B (Table V):

1) Chromosome pairing is in all three genotypes incomplete. The only chromosome where synapsis is complete or nearly so is the isochromosome. If the data for the degree of synapsis achieved at late zygotene are taken at face value, they indicate a more extensive synaptonemal complex formation in the euploid genotype $(43 \%)$, while somewhat lower percentages are found in the two other genotypes lacking the short arm of chromosome 5B (nullisomic 5B, $34 \%$; monoisosomic 5BL, 32\%). However, at this stage there is within the individual genotype a substantial variation in the degree of synapsis and only two nuclei were measured from this stage in the euploid hybrids. Similar problems are encountered at early diplotene, where only the euploid hybrid has been analysed in sufficient detail at this stage to permit a reliable estimate of the degree of synapsis achieved $(32 \%)$ (Tables III and V). It is apparent, however, that no major difference as to the degree of synapsis exists between the three genotypes.

2) In the absence of chromosome 5B there is at early and late zygotene a more than twofold increase in the number of pairing partner exchanges per lateral component when compared to euploid hybrids. At mid zygotene there is only an increase of $41 \%$. The number of pairing partner exchanges per lateral component in the nullisomic $5 \mathrm{~B}$ hybrids exceeds that found in the monoisosomic 5BL hybrids by $70 \%$ at late zygotene, while the numbers in the two hybrid materials at mid zygotene are approximately the same.

3) At metaphase $I$ in the nullisomic 5B, the euploid and the monoisosomic 5BL hybrid there are a mean number of chiasmata of about $7,0.7$, and 0.05 per cell (excluding the chiasmata in the isochromosome). One copy of chromosome $5 \mathrm{~B}$ accordingly results in a tenfold reduction in the number of chiasmata compared to the number of chiasmata formed in the absence of chromosome 5B while two copies of the long arm of this chromosome results in a further tenfold reduction in chiasma frequency. This shows that chromosome $5 \mathrm{~B}$ has a dual effect on meiosis in wheat-rye hybrids, its absence causing a reduction in the stringency of synapsis and permitting crossing over between homoeologues. The very strong suppression of chiasma formation in the presence of the isochromosome for the long arm was unexpected as haploids of wheat or wheat-rye hybrids carrying either the normal chromosome $5 \mathrm{~B}$ or an isochromosome for the long arm of $5 \mathrm{~B}$ have been reported to have similar chiasma frequencies $(20,22)$. Likewise, disomy for chromosome 5B in hybrids between Chinese Spring wheat and rye has been reported not to effect the chiasma frequency (16). A duplication of a short interstitial segment on the long arm of chromosome 5B, probably containing the $\mathrm{Ph}$ locus (7) has, however, in hybrids between tetraploid $\mathrm{T}$. turgidum $\mathrm{cv}$. Capelli (genomic constitution $2 \times \mathrm{A}, 2 \times \mathrm{B}$ ) and various Aegilops species been reported to suppress chiasma formation, as the number of chiasmata in nearly all hybrids was somewhat lower than found in hybrids carrying the normal chromosome 5B. There were, though, substantial differences among the hybrids, indicating that the degree of suppression is dependent on the genotype of the Aegilops species (12).

4) The data for the spread zygotene nuclei of the monoisosomic 5BL hybrids suggest that the isochromosome in all nuclei synapses into a perfect hairpin, illustrating that synapsis between homologous/identical chromosome segments proceeds much more rapidly than pairing and synaptonemal complex formation between homoeologous and nonhomologous segments. 
X. WANG \& P.B. HOLm: Synapsis in wheat-rye hybrids
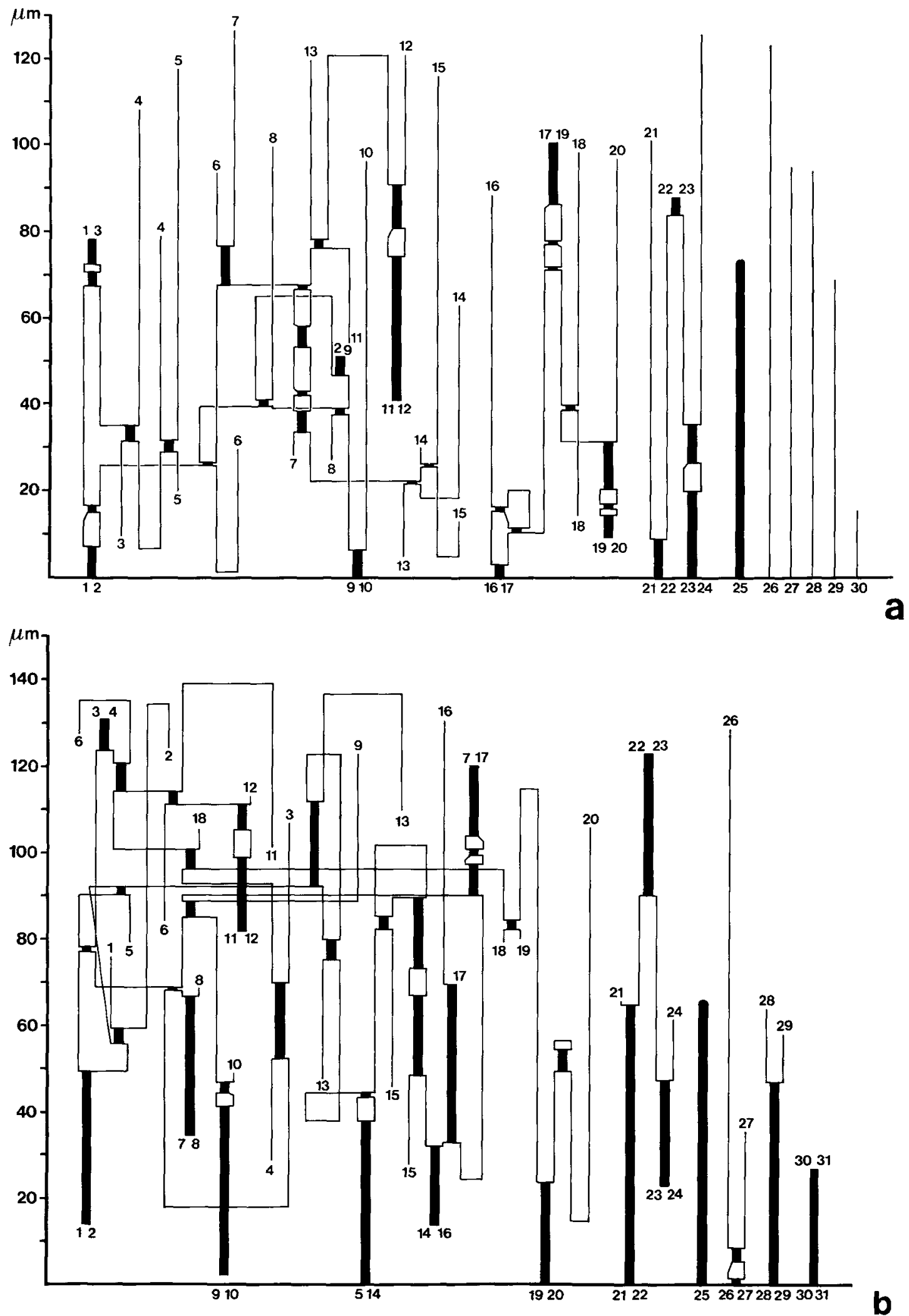


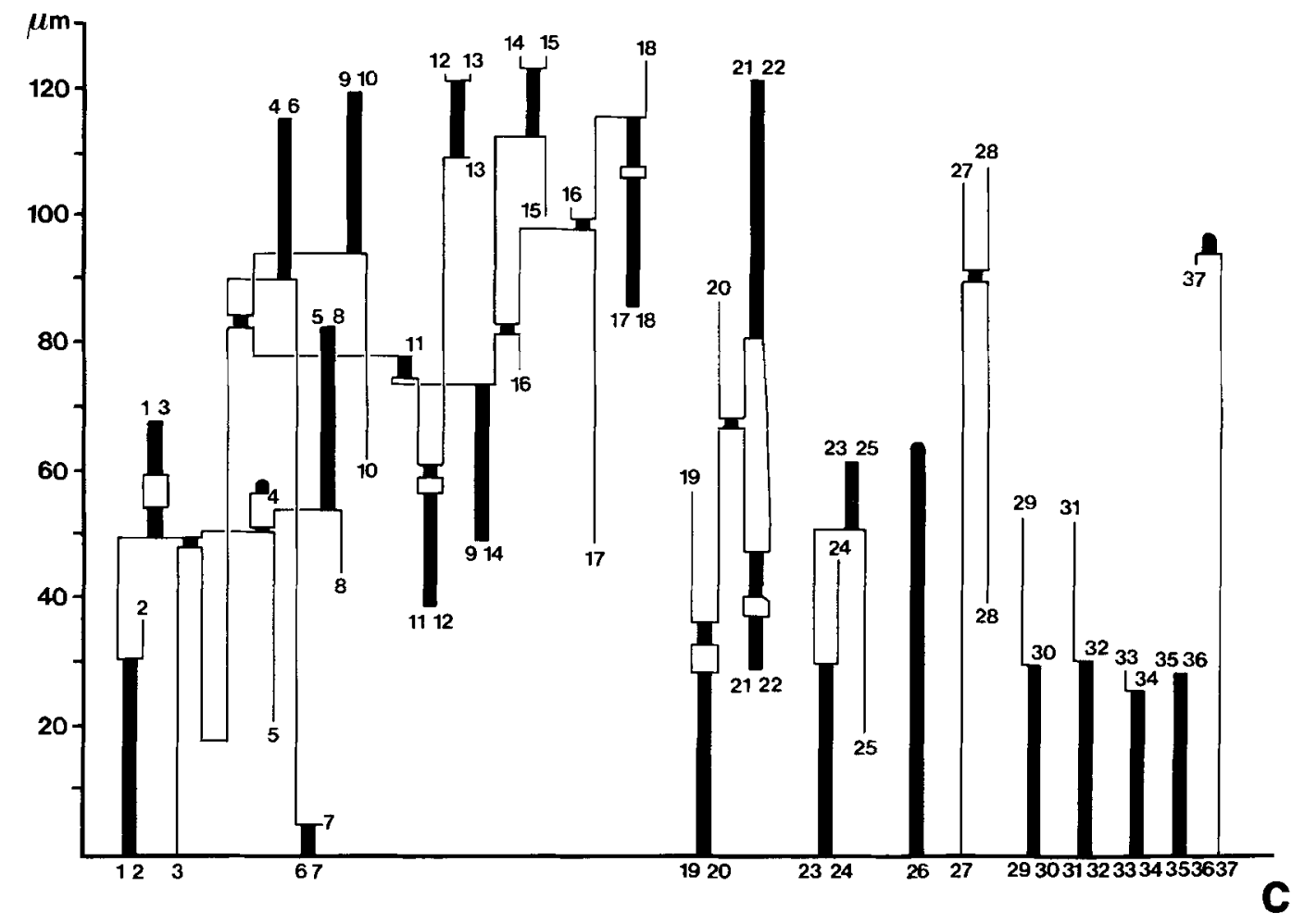

Figure 11. Idiograms of the lateral component complement from three late zygotene nuclei of wheat-rye hybrids monoisosomic for 5BL (Figure 12a, LZ1, 18\% pairing; Figure 12b, LZ2, 29\% pairing and Figure 12c, LZ6, 42\% pairing). In all three nuclei the isochromosome forms a completely paired hairpin. For explanation of symbols see legend to Figure 4.

Table V. Degree of pairing, number of pairing partner exchanges per lateral component (LC) engaged in synapsis and number of lateral components involved in multiple associations (involving more than four LC's) in hybrids between wheat and rye nullisomic for chromosome 5B (0x5B), euploid hybrids (1 $\times 5 B)$ and hybrids monoisosomic for the long arm of chromosome 5B $(2 \times 5 \mathrm{BL})$. ND, not determined.

\begin{tabular}{llcccc}
\hline Stage & $\begin{array}{l}\text { Geno- } \\
\text { type }\end{array}$ & $\begin{array}{l}\text { Number } \\
\text { of nuclei }\end{array}$ & $\begin{array}{l}\% \\
\text { pairing }\end{array}$ & $\begin{array}{l}\text { Number of LC's } \\
\text { in multiple } \\
\text { associations }\end{array}$ & $\begin{array}{l}\text { Number of } \\
\text { pairing partners } \\
\text { per LC }\end{array}$ \\
\hline Early & $0 \times 5 \mathrm{~B}$ & 2 & 8 & 25 & 2.04 \\
zygotene & $1 \times 5 \mathrm{~B}$ & 3 & 13 & 23 & 0.89 \\
Mid & $2 \times 5 \mathrm{BL}$ & $\mathrm{ND}$ & $\mathrm{ND}$ & $\mathrm{ND}$ & ND \\
zygotene & $0 \times 5 \mathrm{~B}$ & 8 & 15 & 29 & 1.14 \\
& $1 \times 5 \mathrm{~B}$ & 2 & 31 & 25 & 0.81 \\
Late & $2 \times 5 \mathrm{BL}$ & 6 & 29 & 22 & 1.19 \\
zygotene & $0 \times 5 \mathrm{~B}$ & 12 & 34 & 28 & 1.07 \\
& $1 \times 5 \mathrm{~B}$ & 2 & 43 & 14 & 0.47 \\
Early & $2 \times 5 \mathrm{BL}$ & 6 & 32 & 17 & 0.63 \\
diplotene & $0 \times 5 \mathrm{~B}$ & 2 & 52 & ND & ND \\
& $1 \times 5 \mathrm{~B}$ & 9 & 32 & ND & ND \\
\hline
\end{tabular}




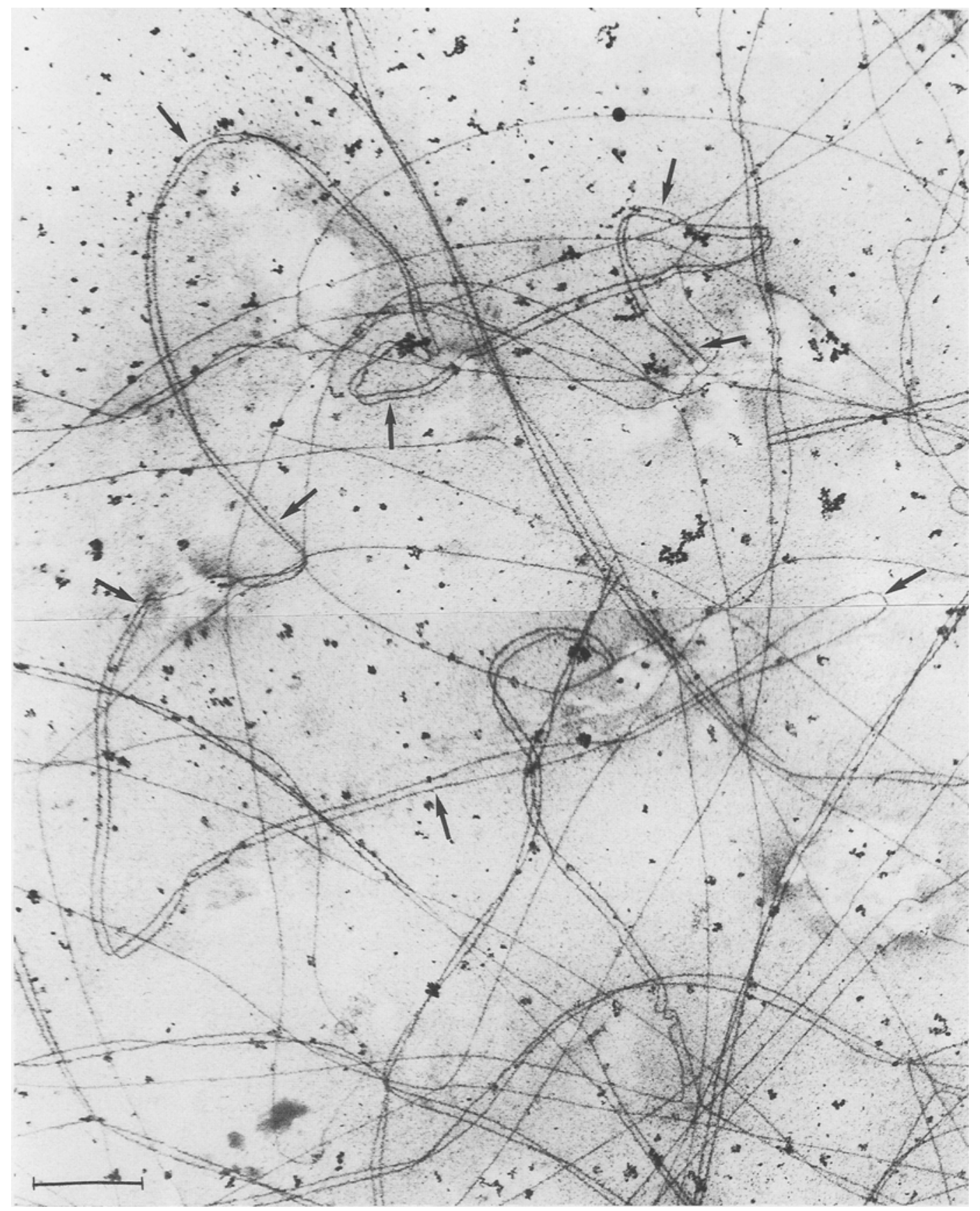

Figure 12. Electron micrograph of the isochromosome for the long arm of chromosome 5B. The isochromosome is completely paired forming a large hairpin (arrows). (Bar $=10 \mu \mathrm{m}$ ) 
Synaptonemal complex formation in this chromosome is further facilitated by the fact that only two telomeres have to find each other as the two arms at the other end are joined into a common centromere. This probably also explains why pairing and chiasma formation in isochromosomes appears to be unaffected by colchicine (4), while severe asynapsis in hexaploid wheat is induced for the remainder of the complement $(3,5)$. As colchicine appears to affect the movements of chromosomes during synapsis $(10,23)$, synaptonemal complex formation may proceed from the centromere towards the telomere relatively unaffected while the other chromosomes have to move to find a pairing partner. In the present study only $20 \%$ of the isochromosomes appeared to have formed ring univalents by chiasma formation between the two arms. However, as described in section 3.1 only those cases were counted where the ring univalents were easily identifiable, and the actual frequency of ring univalents may therefore be somewhat higher. It thus remains unknown if the strong suppression of crossing over between the homoeologues observed in this genotype also has some effect on crossing over between the homologous/identical arms of the isochromosome.

\section{ACKNOWLEDGEMENTS}

We are indebted to Professor DIter voN Wettstein, Dr. Søren W. Rasmussen and Cand. scient. BENTE WISCHMANN for discussion and review of the manuscript. The expert technical assistance of BIBI STAMPE ANDERSEN, JEAN Sage, Nina Rasmussen and AnN-Sofi SteinHOLTZ is gratefully acknowledged. The Royal Danish Academy of Sciences and Letters is thanked for having provided one of us (P.B.H.) with a Niels Bohr Scholarship. The work was also supported by grant BI6-E-168-DK from the Commision of the European Communities.

\section{REFERENCES}

1. Abirachid-Darmency, M., Y. Cauderon \& D. ZICKLER: Meiotic chromosome pairing in three F1 (Triticum-Secale) hybrids: A comparative approach in light and electron microscopy. Biol. Cell $51,365-372$ (1984)
2. Dhaliwal, H.S., B.S. Gill \& J.G. Waines: Analysis of induced homoeologues pairing in a ph mutant wheat $x$ rye hybrid. J. Heredity 68 , 206-209 (1977)

3. DOVER, G.A. \& R. RILEY: The effect of spindle inhibitors applied before meiosis on meiotic chromosome pairing. J. Cell Sci. 12, 143-161 (1973)

4. DRISCOLl. C.J. \& N.L. DarveY: Chromosome pairing: effect of colchicine on an isochromosome. Science 169, 290-291 (1970)

5. DRISCOLL, C.J.,N.L. DARVEY \& H.N. BARBER: Effect of colchicine on meiosis of hexaploid wheat. Nature 216, 687-688 (1967)

6. DVOR̆AK, $\mathbf{J}$ : Effect of rye on homoeologous chromosome pairing in wheat $\times$ rye hybrids. Can. J. Genet. Cytol. 19, 549-556 (1977)

7. DvoŕáA, J., K.C. CHEN \& B. Giorgr: The C-band pattern of a Ph-mutant of durum wheat. Can. J. Genet. Cytol. 26, 360-363 (1984)

8. GILLIES, C.B.: An electron microscopical study of synaptonemal complex formation at zygotene in rye. Chromosoma 92, 165-175 (1985)

9. Holm, P.B.: Chromosome pairing and chiasma formation in allohexaploid wheat, Triticum aestivum analyzed by spreading of meiotic nuclei. Carlsberg Res. Commun. 51, 239-294 (1986)

10. Holm, P.B. \& X. WANG: The effect of chromosome 5B on synapsis and chiasma formation in wheat, Triticum aestivum cv. Chinese Spring. Carlsberg Res. Commun. 53, 191-208 (1988)

11. Hutchinson, J., T.E. Miller \& S.M. Reader: Cbanding at meiosis as a means of assessing chromosome affinities in the Triticeae. Can. J. Genet. Cytol. 25, 319.323 (1983)

12. JAMPATES, R. \& J. DVORAK: Location of the Ph1 locus in the metaphase chromosome map and the linkage map of the $5 \mathrm{~Bq}$ arm of wheat. Can. J. Genet. Cytol. 28, 511-519 (1986)

13. KOEBNER, R.M.D. \& K.W. SHEPHERD: Induction of recombination between rye chromosome $1 R L$ and wheat chromosomes. Theor. Appl. Genet. 71, 208-215 (1985)

14. Mettin, D., R. SChlegel, W.D. Bluthner \& M. WEINREICH: Giemsa-banding von MI-Chromosome bei Weizen-Roggen-Bastarden. Biol Zbl. 95, 35-41 (1976)

15. Miller, T.E.: The homoeologous relationship between the chromosomes of rye and wheat. Current status. Can. J. Genet. Cytol. 26, 578-589 (1984)

16. Miller, T.E. \& S.M. REader: The effect of increased dosage of wheat chromosomes on chromosome pairing and an analysis of the chiasma frequencies of individual wheat bivalents. Can. J. Genet. Cytol. 27, 421-425 (1985)

17. Naranjo, T.: Preferential occurence of wheat-rye meiotic pairing between chromosomes of homoe- 
ologous group 1. Theor. Appl. Genet. 63, 219-225 (1982)

18. Naranjo, T. \& O. Palla: Genetic control of chromosome pairing in rye. Heredity 48, 57-62 (1982)

19. RILEY, R.: The diploidisation of polyploid wheat. Heredity 15, 407-429 (1960)

20. RILEY, R.\& V.CHAPMAN: The effect of the deficiency of the long arm of chromosome 5B on meiotic pairing in Triticum aestivum. Wheat Inform. Serv. 17-18, 12-15 (1964)

21. Riley, R. V.Chapman \& T.E.MILleR: The determination of meiotic chromosome pairing. Proc. 4th Int. Wheat Genet. Symp., Columbia, Missouri, pp. 731-738 (1973)

Accepted by E. LuND
22. Riley, R. \& C. Kempanna: The homoeologous nature of the non-homologous meiotic pairing in Triticum aestivum deficient for chromosome $\mathrm{V}$ (5B). Heredity 18, 287-306 (1963)

23. Salonen, K., J. Paranko \& M. Parvinen: A colcemid-sensitive mechanism involved in regulation of chromosome movements during meiotic pairing. Chromosoma 85, 611-618 (1982)

24. SEARS, E.R.: An induced mutant with homoeologous pairing in common wheat. Can. J. Genet. Cytol. 19, 585-593 (1977)

25. WANG, $X$ : Chromosome pairing analysis in haploid wheat by spreading of meiotic nuclei. Carlsberg Res. Commun. 53, 135-166 (1988) 